Citation: Gurung, T.R. Stewart, R.A. Sharma, A.K. Beal, C.D. (2014) Smart

meters for enhanced water supply network modelling and infrastructure

planning, Resources, Conservation and Recycling, 90, 34-50.

http://dx.doi.org/10.1016/j.resconrec. 2014.06.005.

\title{
Smart meters for enhanced water supply network modelling and infrastructure planning
}

\section{Authors:}

\section{Thulo Ram Gurung}

PhD Candidate, Griffith School of Engineering, Griffith University, Gold Coast Campus, QLD 4222, Australia, E-mail: ram.gurung@griffithuni.edu.au

\section{Rodney Anthony Stewart*}

Director, Centre for Infrastructure Engineering \& Management, Griffith University, Gold Coast Campus, 4222, Australia, Phone: +61 75552 8778, E-mail: r.stewart@griffith.edu.au

*Corresponding author

\section{Ashok K. Sharma}

Principal Research Scientist, CSIRO Land and Water, Highett, VIC 3190, Australia, E-mail: Ashok.sharma@csiro.au

\section{Cara D. Beal}

Research Fellow, Smart Water Research Centre, Griffith University, Southport, QLD 4222, Australia, E-mail: c.beal@griffith.edu.au 


\begin{abstract}
To design water distribution network infrastructure, water utilities formulate daily demand profiles and peaking factors. However, traditional methods of developing such profiles and peaking factors, necessary to carry out water distribution network modelling, are often founded on a number of assumptions on how top-down bulk water consumption is attributed to customer connections and outdated demand information that does not reflect present consumption trends; meaning infrastructure is often unnecessarily overdesigned. The recent advent of high resolution smart water meters allows for a new novel methodology for using the continuous 'big data' generated by these meter fleets to create evidence-based water demand curves suitable for use in network models. To demonstrate the application of the developed method, high resolution water consumption data from households fitted with smart water meters were collected from the South East Queensland and Hervey Bay regions in Australia. Average day (AD), peak day (PD) and mean day maximum month (MDMM) demand curves, often used in water supply network modelling, were developed from the herein created methodology using both individual end-use level and hourly demand patterns from the smart meters. The resulting modelled water demand patterns for $\mathrm{AD}, \mathrm{PD}$ and MDMM had morning and evening peaks occurring earlier and lower main peaks (AD: 12\%; PD: 20\%; MDMM: 33\%) than the currently used demand profiles of the regions' water utility. The paper concludes with a discussion on the implications of widespread smart water metering systems for enhanced water distribution infrastructure planning and management as well as the benefits to customers.
\end{abstract}

Keywords: diurnal patterns; smart meters; peaking factors; water demand profiles; water supply network modelling; water end use.

\title{
1 Introduction
}

\subsection{Water distribution network modelling and infrastructure planning}

Water distribution network modelling is an essential component of water supply planning, as it allows water engineers and planners to understand how the water supply system operates, enabling them to make informed decisions regarding operation and planning to achieve the required standards of service. Water supply network design usually incorporates parameters such as water consumption values and flow rate, design peak factors, pressure requirements and physical pipe properties (e.g. material and size). While information on pressure requirements is readily available from local guidelines (e.g. DERM, 2010; SEQ Code, 2013) and pipe properties can be ascertained from the relevant hydraulic literature and local guidelines, estimating water demands accurately is more difficult due to highly variable influencing factors such as demographics and land use, climate, economic and social factors, technology, government intervention, and pricing (Beal and Stewart, 2013; Browne et al., 2013; Lee et al., 2010; Parker and Wilby, 2013)

Water demand varies during the day, with demand generally lowest during the night and highest in the morning and early evening hours, resulting in double peaks concentrated over these two periods; the higher of which is termed a daily peak demand. This variation in daily water demand is also referred to as a diurnal demand curve. Over an annual analysis period, water utilities define certain peak demands to assist in infrastructure design. Peak hour (PH) demand exists in a peak day (PD), which is the maximum day demand over a 12-month period, and is utilised mainly in the design of pipe infrastructure. Additionally, in Queensland, Australia, the average of the highest moving average 30day water demand, the mean day at maximum month (MDMM), is utilised to reflect demand persistence in response to climatic condition (DERM, 2010). This average is used mainly in the sizing 
of pumps and reservoirs. Peaking factors are thus derived relative to average day (AD) demand; that is, average consumption over a 12-month period, to assist water utilities in designing water infrastructure. A review of peaking factors is presented in Table 1.

Table 1 Range of peaking factors from various sources

\begin{tabular}{|c|c|c|c|c|c|}
\hline Source & Location & $\begin{array}{l}\text { Population/ Res. } \\
\text { Density }\end{array}$ & PD:AD & PH:AD & MDMM:AD \\
\hline WSAA (2004) & Australia & $\begin{array}{l}>10,000 \\
<2,000\end{array}$ & $\begin{array}{l}1.5 \\
2.0\end{array}$ & $\begin{array}{l}2.0 \\
5.0\end{array}$ & N/A \\
\hline DERM (2010) & Queensland, Australia & $\begin{array}{l}>5,000 \\
<5,000\end{array}$ & $\begin{array}{l}1.5-2.7 \\
1.9-2.3\end{array}$ & $\begin{array}{l}3.6-4.0 \\
3.6-4.5\end{array}$ & $\begin{array}{l}1.4-1.5 \\
1.5-1.7\end{array}$ \\
\hline \multirow{2}{*}{$\begin{array}{l}\text { SEQ Code } \\
\text { (2013) }\end{array}$} & Gold Coast, Australia & $\begin{array}{l}\text { Residential Single } \\
\text { (detach) }\end{array}$ & 2.12 & 6.03 & 1.75 \\
\hline & $\begin{array}{l}\text { Brisbane, Redland, Ipswich, } \\
\text { Logan, Moreton Bay, Australia }\end{array}$ & Low - High Density & 2.0 & $3.5-4.0$ & 1.5 \\
\hline CSIR (2003) & South Africa & Low - High Density & 1.5 & $3.6-4.0$ & N/A \\
\hline Ysusi (2000) & United States & Undefined & $1.8-2.8$ & $2.5-4.0$ & N/A \\
\hline MOE (2008) & Canada & $\begin{array}{l}>10,000 \\
<10,000\end{array}$ & $\begin{array}{r}1.5-1.9 \\
2.0-2.75\end{array}$ & $\begin{array}{r}2.25-2.85 \\
3.0-4.13\end{array}$ & N/A \\
\hline $\begin{array}{l}\text { Twort et al. } \\
\text { (2000) }\end{array}$ & UK & Undefined & $1.22-1.7$ & $1.9-3.0$ & N/A \\
\hline
\end{tabular}

Diurnal consumption patterns and their peak demands and periods provide useful information on system flow rates, enabling the configuration and calibration of network distribution models and for integrated urban water planning (Cole and Stewart, 2012). The ability to estimate and predict present and future consumption demand is a key component in a water supply system to ensure levels of service standards are not compromised. Short-term forecasts are most useful in the daily management and operation of a network, while long-term forecasts are more suited for future planning and design, as projected population growth typically results in an increased demand (Carragher et al., 2012; Parker and Wilby, 2013). In current industry practice, two approaches are used in developing these forecasts, namely, topdown modelling and bottom-up modelling. A brief description of the two modelling techniques is presented below, however, in brief, top-down modelling is often plagued with a number of assumptions on how demand is proportioned to different categories, with the latter approach often completed with poor resolution data coupled with statistical models. The herein formulated method overcomes these problems by utilising up-to-date high resolution smart meter datasets in order to disaggregate consumption into end use or micro-component categories for bottom-up diurnal demand patterns of indoor consumption, and hourly demand disaggregation to identify outdoor proportions of consumption over a range of seasons. This approach provides an evidence-based bottom-up model of daily diurnal demand, which differentiates itself from the current approach that is highly dependent on outdated secondary data to create end use demand estimates.

\subsubsection{Top-down modelling}

A top-down approach to water demand modelling allocates a demand multiplier pattern to demand nodes across a broad spatial scale, and assigns correction factors to account for total water demand for each of the nodes (Blokker et al., 2010a; Carragher et al., 2012). Traditional network modelling essentially requires the gathering of information, such as bulk meter data, water production, demand patterns from pumping stations and customer billing data, and a series of assumptions made to separate the information into the relevant demand components. Historically determined water demand patterns are also utilised and adjusted accordingly to reflect the change to recent consumption values and peak factors, with the assumption that base consumer usage patterns remain the same (GCW, 2009). 
The standard demand patterns are not able to represent water demands' stochastic nature (Todorovic et al., 2011) or the inverse relationship of peaking factors to connections/population size - peaking factors reduce with increasing connected households (Todorovic et al., 2011). Furthermore, water demand profiles are usually gathered after long intervals, such as every three to five years, and may be outdated and not relevant to current periods. Hence, such patterns are of little use in modelling small or detailed network models or for predicting future water demands (Todorovic et al., 2011).

\subsubsection{Bottom-up modelling}

A bottom-up demand modelling approach combines water demand patterns modelled for each household within a supply zone, and allocates individual demand patterns to each connection within the network to more accurately determine demand on a small spatial scale (Blokker et al., 2010a; Carragher et al., 2012). This essentially requires the collection of information on a smaller scale, normally at an individual household level, providing a finer level of detail of the gathered water consumption data. Furthermore, as the data is empirically gathered for each household, this eliminates the need to make assumptions required in the top-down approach.

Recent studies have featured the development of diurnal water consumption patterns that do not use direct-demand measurements. This includes stochastic and probabilistic methods of demand modelling using statistical information of water appliances and residential users at varying levels of temporal and spatial variability (e.g., Blokker et al., 2010b; Duncan and Mitchell, 2008; Thyer et al., 2009). While these models present a good fit of simulated patterns to observed data, they are not supported fully by empirically gathered mode of demand generation, and require calibration and validation to predict future and instantaneous diurnal demand patterns. However, the absence of leakage estimation in such models, which can account for around 2\% to 6\% (Athuraliya et al., 2012; Beal and Stewart, 2011) of overall household consumption, makes calibration more difficult (Rathnayaka et al., 2011). Furthermore, the difficulty in managing the complex correlations between the various parameters, and the lack of data representing the relationships between individual end uses and the factors influencing their water consumption, limits the ability of these models to simulate end-use patterns at development, city and regional scales (Rathnayaka et al., 2011).

\subsection{Advent of smart water metering}

Advancements in metering and data communications technology have made it possible to record household water usage data through smart water meters. They can automatically and electronically capture, collect and communicate water usage readings in real time or close to real time (Boyle et al., 2013; Cole and Stewart, 2012). This electronic data can be transferred by automated means (e.g. GSM, GPRS, CDMA, drive by) to servers for storage and the subsequent processing and analysis of data (Boyle et al., 2013). Smart water metering would be expected, as a minimum, to convey daily meter readings between the water utility and the water meter, and potentially to customers as well. Finer levels of data capture (in seconds, minutes or hourly) could also be programmed into the loggers to enable more detailed analysis to be carried out (e.g. Beal and Stewart, 2011; Britton et al., 2013; Mead, 2008; Willis et al., 2011a). This is unlike traditional methods of periodical (accumulation) metering, where household water consumption is typically only manually read on a monthly or quarterly basis meaning that daily trends of consumption need to be estimated for planning purposes. Such automated technology would provide benefits for both water authorities and consumers in monitoring and controlling water consumption (Stewart et al., 2010) and enable alternative pricing mechanisms such as time-of-use or seasonal tariffs (Cole et al., 2012; Parker and Wilby, 2013). However, while the benefits of accurate just-in-time (JIT) network modelling have been mentioned in recent years, there are few examples in the literature demonstrating how smart meters can be used for this purpose. 


\subsubsection{Smart meter enabled end-use studies}

End-use studies are important as they have direct implications on demand management programmes and installation of more efficient plumbing fixtures (Proenca and Ghisi, 2010). Smart water meters have been utilised in a number of residential end-use water consumption studies. In these studies, smart water meters were programmed to collect high-resolution data (e.g. 0.01-0.02 litres per pulse [L/pulse] range) at recording intervals of five or ten seconds (e.g. Beal and Stewart, 2011; Willis et al., 2011a; Mead, 2008). This allowed the consumption data to be disaggregated into individual end-use categories (e.g. clothes washer, toilets, shower) using the end-use event recognition software, Trace Wizard ${ }^{\circledR}$. (Aquacraft, 2010). Disaggregating water consumption to its end-use components is important, as this can help to accurately determine how frequently, and where, water is used by residents in their homes, allowing a more proactive approach to water demand management and planning (Carragher et al., 2012; Cole and Stewart, 2012).

Typical household end-use studies report total and individual end-use consumption values (per capita and/or per household) as well as such details as diurnal consumption patterns, peak flows and the time of peaks (e.g. Beal and Stewart, 2011; Mead, 2008; Willis et al., 2011a). These studies provide a useful insight into the individual household appliance consumptions and average peak flows generated from a single household, for different areas, which form the basis of predicting future water demands. End-use studies capitalising on smart water meters are shown in Table 2.

Table 2 Summary of smart water metered end-use studies

\begin{tabular}{|c|c|c|c|c|}
\hline Study & Location & $\begin{array}{l}\text { No. of } \\
\text { Homes }\end{array}$ & Results in $L / p / d$ & Reference \\
\hline \multirow{5}{*}{$\begin{array}{l}\text { South East Queensland } \\
\text { Residential End Use } \\
\text { Study: Final Report } \\
\text { (reduced sample sizes due } \\
\text { to Jan } 2011 \text { flooding and } \\
\text { logger failure) }\end{array}$} & \multirow{5}{*}{$\begin{array}{l}\text { South East } \\
\text { Queensland, } \\
\text { QLD, Australia }\end{array}$} & 252 & Winter 2010: Total 145.3, Indoor 138.4, Outdoor (OD) 7 & \multirow{5}{*}{$\begin{array}{l}\text { Beal and } \\
\text { Stewart } \\
(2011)\end{array}$} \\
\hline & & 219 & Summer 2010/11: Total 125.3, Indoor 100.5, OD 4.8 & \\
\hline & & 110 & Winter 2011: Total 144.9, Indoor 138.2, OD 6.7 & \\
\hline & & 93 & Summer 2011/12: Total 137.6, Indoor 120, OD 17.6 & \\
\hline & & 83 & Autumn 2012: Total 144.4, Indoor 120.4, OD 24 & \\
\hline $\begin{array}{l}\text { Melbourne Residential } \\
\text { Water End Uses Winter } \\
\text { 2010/ Summer } 2012 \\
\end{array}$ & $\begin{array}{l}\text { Melbourne, } \\
\text { VIC, Australia }\end{array}$ & 300 & $\begin{array}{l}\text { Winter 2010: Total 114, Indoor 110, OD } 4 \\
\text { Summer 2012: Total 147, Indoor 120, OD } 27\end{array}$ & $\begin{array}{l}\text { Redhead et al. } \\
\text { (2013) }\end{array}$ \\
\hline $\begin{array}{l}\text { Yarra Valley Future } \\
\text { Water: Residential Water } \\
\text { Use Study (Winter 2010/ } \\
\text { Summer 2012) }\end{array}$ & $\begin{array}{l}\text { Yarra Valley, } \\
\text { VIC, Australia }\end{array}$ & 100 & $\begin{array}{l}\text { Winter 2010: Total 109, Indoor 106, OD } 3 \\
\text { Summer 2012: Total 127.9, Indoor 108.1, OD } 19.8\end{array}$ & $\begin{array}{l}\text { Roberts et al. } \\
\text { (2011), } \\
\text { Athuraliya et } \\
\text { al. (2012) }\end{array}$ \\
\hline \multirow[t]{2}{*}{$\begin{array}{l}\text { Gold Coast Water Saver } \\
\text { End Use Study }\end{array}$} & \multirow[t]{2}{*}{$\begin{array}{l}\text { Gold Coast, } \\
\text { QLD, Australia }\end{array}$} & $\begin{array}{l}151 \\
127\end{array}$ & $\begin{array}{l}\text { Winter 2008: Total 157, Indoor 138.4, OD } 18.6 \\
\text { Summer 08/09: Single ret - Total 158.4, Indoor 145.7, } \\
\text { OD 12.7; Dual ret - Total 143.5, Indoor 134.4, OD } 13.1\end{array}$ & \multirow[t]{2}{*}{$\begin{array}{l}\text { Willis et al. } \\
(2009,2011 a)\end{array}$} \\
\hline & & 134 & $\begin{array}{l}\text { Summer 09/10: Single ret - Total 171.9, Indoor 150, OD } \\
\text { 21.9; Dual ret - Total 183.6, Indoor 136, OD } 47.6\end{array}$ & \\
\hline $\begin{array}{l}2010 \text { - Perth Residential } \\
\text { Water Study } 2008 \text { - } 2009\end{array}$ & $\begin{array}{l}\text { Perth, WA, } \\
\text { Australia }\end{array}$ & 1,868 & Total 290.4, Indoor 164.6, OD 126 & $\begin{array}{l}\text { Water } \\
\text { Corporation } \\
(2010)\end{array}$ \\
\hline $\begin{array}{l}2008 \text { - Auckland Water } \\
\text { Use Study (AWUS) Final } \\
\text { Report }\end{array}$ & $\begin{array}{l}\text { Auckland, New } \\
\text { Zealand }\end{array}$ & 51 & $\begin{array}{l}\text { Summer 2008: Total 188, Indoor 156.1, OD } 31.9 \\
\text { Winter 2008: Total 175, Indoor 164.5, OD } 10.5\end{array}$ & $\begin{array}{l}\text { Heinrich } \\
\text { (2008) }\end{array}$ \\
\hline $\begin{array}{l}2007 \text { - Water End-use and } \\
\text { Efficiency Project - Final } \\
\text { Report }\end{array}$ & $\begin{array}{l}\text { Kapiti Coast, } \\
\text { New Zealand }\end{array}$ & 12 & $\begin{array}{l}\text { Winter 2006: Total 168.1, Indoor 154.2, OD } 13.9 \\
\text { Summer 2006/07: Total 203.9, Indoor 159.9, OD } 44.5\end{array}$ & $\begin{array}{l}\text { Heinrich } \\
\text { (2007) }\end{array}$ \\
\hline $\begin{array}{l}2004 \text { - Tampa Water } \\
\text { Department Residential } \\
\text { Water Conservation Study }\end{array}$ & $\begin{array}{l}\text { Tampa, Florida, } \\
\text { USA }\end{array}$ & 26 & $\begin{array}{l}\text { Baseline: Indoor } 292 \\
\text { Post retrofit: Indoor } 147\end{array}$ & $\begin{array}{l}\text { Mayer et al. } \\
\text { (2004) }\end{array}$ \\
\hline
\end{tabular}


Along with end-use studies, high resolution smart water meters have been utilised to monitor rainwater tanks connected to individual households (Ferguson, 2011; Lucas et al., 2012; Umapathi et al., 2013), a high-rise commercial building (Cook et al., 2014) and a communal rainwater system (Cook et al., 2013). These meters have also assisted in reporting potential water savings from using efficient household water appliances (Athuraliya et al., 2012; Beal and Stewart, 2011; Heinrich, 2007; Mayer et al., 2004; Willis et al., 2013) and comparing water demand of efficient and non-efficient homes (Carragher et al., 2012). Willis et al. (2010, 2011b) monitored showers fitted with an alarming visual display monitor (Willis et al., 2010) and investigated the relationship between environmental and water conservation attitude on end-use water consumptions (Willis et al., 2011b). Measuring householders' perceived and actual water consumptions was also performed based on smart metering studies (Beal et al., 2013). On a coarser level (5 L/pulse at hourly intervals), smart water meters from the city of Hervey Bay were used to identify and manage households' leaks (Britton et al., 2013), differentiate indoor and outdoor consumption to determine the drivers of peak demand (Cole and Stewart, 2012) and develop and model the impact of innovative time-of-use tariffs which imposed an hourly inclining block penalty targeting outdoor consumption (Cole et al., 2012).

\subsubsection{Smart meters for enhanced water service infrastructure planning}

Studies utilising smart water meters have shown that information collected from these meters allows a better understanding on temporal profiles of household water consumption, furthering their capability to be used as a water infrastructure and management tool. While smart metering itself does not directly reduce daily and peak demand, it has the potential to inform water businesses and their customers of different end-use consumption patterns and leakages. This information could help to reduce demand through almost real-time usage portals and leakage alert messages (Stewart et al., 2010; Britton et al., 2013). Such information has a strong potential to reduce peak demand and defer trunk main upgrades when existing areas are experiencing extensive new in-fill developments.

Current water infrastructure network modelling is based on a top-down model approach, which carries a number of assumptions and often uses out-of-date consumption data. Using smart meters extensively eliminates these assumptions by allowing the inclusion of empirical demand-induced diurnal patterns, which can be updated in a network model instantaneously, thereby ensuring a more robust and dynamic water supply network analysis. Although there are a number of models aimed at developing household water consumption patterns, these are not built empirically but are instead developed through stochastic methods using statistical information.

\section{Research objectives}

This study aims to provide empirical evidence to support the implementation of smart water meters as a feasible tool in improving current practices of demand forecasting and subsequent network modelling. Utilising a data-driven, bottom-up end use approach provides a superior set of diurnal demand patterns and peaking factors that can be used for network modelling and subsequent planning and operational purposes. The four key objectives of this study are to:

- Demonstrate the use of smart water meters as a tool in developing AD, PD and MDMM water demand profiles using a bottom-up empirical approach. 
- Design a new method for developing AD, PD and MDMM water demand profiles using information gathered from smart water meters.

- Implement the developed methodology to create bottom-up derived AD, PD and MDMM daily demand patterns and peak factors for the South East Queensland (SEQ) region.

- Compare bottom-up derived daily diurnal demand patterns with those presently utilised by the region's water utility.

\section{Methodology}

\subsection{Novel method to develop demand patterns from smart water meter fleets}

A methodology has been developed and is presented for the benefit of water professionals around the world to replicate the novel procedure of developing demand curves for use in water supply network modelling. The developed method was not intended to encapsulate the stochastic nature of water demand in individual households, but instead was intended to demonstrate how current modelling practices can be significantly enhanced through the advent of smart metering technologies and the extensive datasets they can provide. Although smart water meters have the ability to provide directdemand values and patterns from individual households, water utilities usually use a set of parameters to forecast and generate demand patterns. Hence, the proposed methodology will use smart water meter data, in conjunction with utilities' $\mathrm{AD}$ consumption values, as an innovative bottom-up approach to develop AD, PD and MDMM demand patterns. The overall methodology is described in the following steps and also depicted in Fig. 1 :

1. Install high resolution smart water meters: Fit smart water meters to a representative number of homes in a water supply zone and create a remote data collection repository for storing and analysing collected data.

2. Data collection and analysis to develop end-use demand patterns: Gather smart water meter data from the water supply zone for a representative period. Use event recognition software, such as Trace Wizard ${ }^{\mathrm{TM}}$, to disaggregate smart water meter consumption to its different end uses. Household water audits and water diaries can also be completed to validate the results of the analysis. Create $\mathrm{AD}$ demand patterns of each end use at regular intervals (e.g. hourly, halfhourly) in relation to the relevant water supply code, on a per capita per hour $(\mathrm{L} / \mathrm{p} / \mathrm{h})$ basis. Consumption profiles for each end use are to be developed separately.

3. Normalise demand patterns for each end use: Normalise the consumption patterns for the different end uses by dividing the demand values at each time interval with their respective average hourly consumption volumes (i.e. each end-use's AD consumption divided by 24 hours) to obtain the water use distribution relative to hourly consumption at each time interval.

4. Estimate indoor and outdoor water consumption splits: Estimate the indoor and outdoor water consumption splits from the smart water meter data or from previous end-use studies for the area/region, if insufficient data is recorded. Use this split to project and estimate the amount of indoor and outdoor water use on $\mathrm{AD}$ using $\mathrm{AD}$ consumption values provided by the utility. The splits in outdoor and indoor consumption may also be obtained from utility guidelines, if available.

5. Update volumes for each indoor end-use: Obtain the percentage consumption contributions of each indoor end use relative to total indoor demand from analysis of the smart water meter data, or from other local end-use studies. Apply the indoor consumption from Step 4 to the indoor end-use distribution to obtain the updated $\mathrm{AD}$ water demand for each end use.

6. Develop final AD pattern: Apply the updated volumes for each end use to their respective normalised demand patterns obtained from Step 3 to develop their individual AD consumption 
profiles. Combine the end-use patterns to obtain the final AD demand pattern for the area. After obtaining the final pattern, normalise it against the assigned $\mathrm{AD}$ consumption value to obtain the factorised diurnal pattern for the area.

7. Develop peak demand curves: Obtain peak demand curves for PD and MDMM, following a similar procedure to the above steps, but with peak factors required to adjust indoor and outdoor peak demands. The key components of this step are as follows:

i. Identify the occurrences of PD and MDMM for the smart water meter-fitted water supply zone.

ii. Develop the normalised demand patterns for PD and MDMM for each end use.

iii. Obtain the indoor and outdoor peak factors for PD and MDMM (i.e. Outdoor/ indoor peak demand divided by the corresponding outdoor/ indoor demand on $\mathrm{AD}$ ).

iv. Apply these factors on the utility's indoor and outdoor split on AD (obtained in Step 4) to estimate the indoor and outdoor demands on PD and MDMM.

v. Obtain the indoor end-use distribution with respect to total indoor consumption for PD and MDMM. Apply consumption from previous step to obtain the updated demands of each end use on PD and MDMM.

vi. Apply updated demands for all end uses on their respective normalised patterns to develop individual end-use consumption profiles for PD and MDMM.

vii. Combine the individual end-use consumption patterns to develop the overall PD and MDMM consumption profiles.

The outlined methodology is relevant for areas with high resolution smart water meters, allowing for the separation of household water consumption data to the various end uses. For an area utilising lower resolution smart water meters e.g. 1 litre at hourly intervals, segregation of data into the relevant end uses is not possible. Instead, a threshold flow can be determined to split the indoor and outdoor consumption, as applied by Cole and Stewart (2012) to enable separation of these two particular uses. In this instance, the indoor pattern can be taken as one end use, instead of the accumulation of different end uses, and the above methodology adjusted accordingly to reflect this. The required water demand patterns can then be developed.

For the purpose of this study, non-revenue water (NRW), which is the unbilled water prior to water supply reaching households (DERM, 2010; GCW, 2009), will not be considered, as the study focusses on direct household water consumption. 


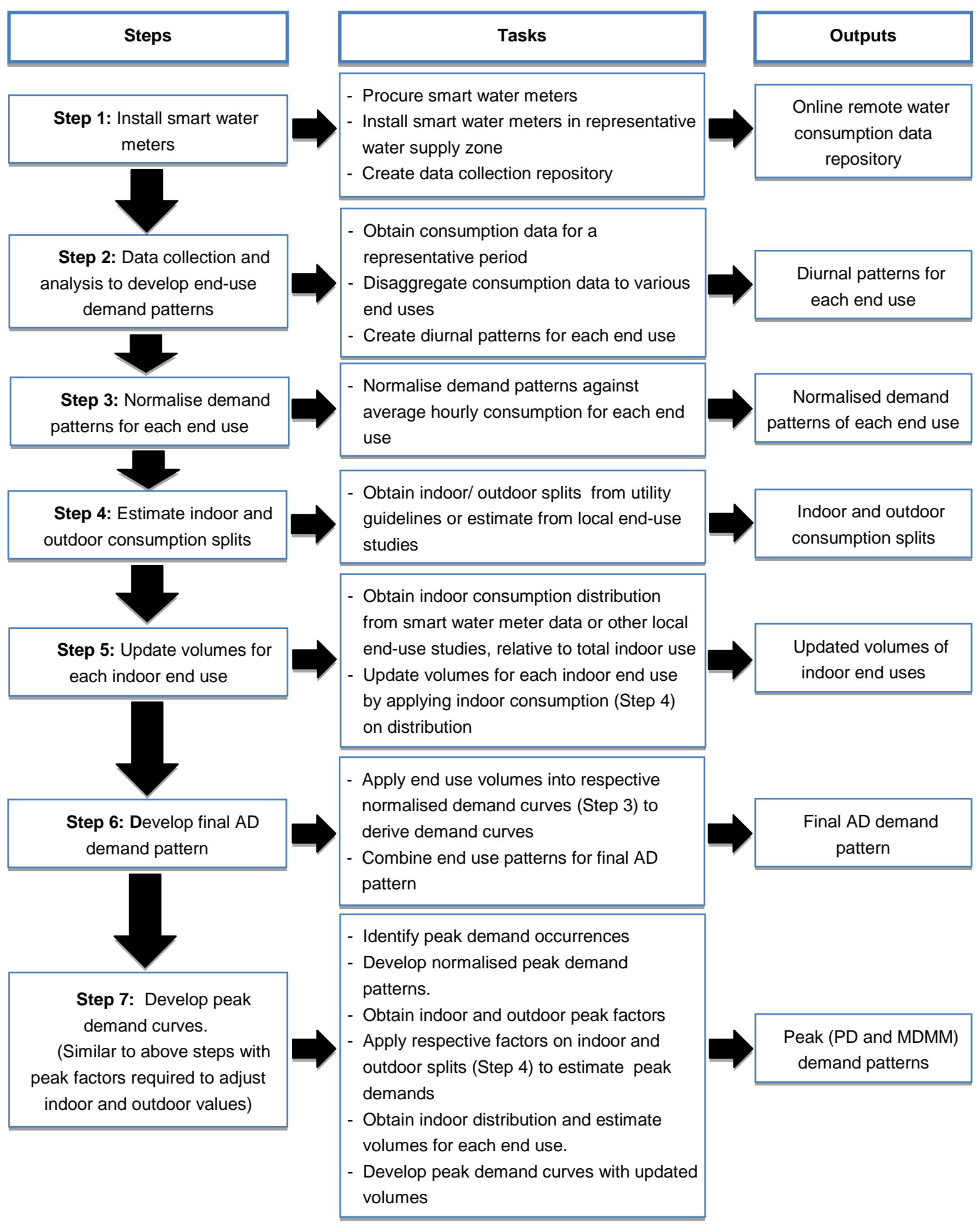

Fig. 1 Schematic of the methodology

\section{Method application in the SEQ region}

\subsection{Step 1: Install smart water meters}

The installation of smart water meters, able to collect water consumption data of at least a resolution of $1 \mathrm{~L}$ every hour, is required to follow most of the steps of the methodology described above. Ideally, a representative sub-sample within the network is equipped with smart water meters that can capture consumption data at very high resolutions (e.g. 0.01 to $0.02 \mathrm{~L} / \mathrm{pulse}$ ) at regular intervals (e.g. 5-10 
seconds) to allow for the breakdown of water consumption data to its different end uses. Having large fleets of such very high resolution smart meters producing water end use datasets is presently not feasible due to the requirement for manual flow trace analysis, which is a resource intensive process. However, promising research by Nguyen et al. (2013a, 2013b and 2014) and Fontdecaba et al. (2013) to automate this process, makes this possible in the near future. Given that high resolution end use data was available for this study, it has been adopted here to demonstrate the full application of the developed methodology described in Fig. 1.

\subsection{Step 2: Data collection and analysis to develop end-use demand patterns}

\subsubsection{Data collection and analysis}

The study sample for the current research was obtained from the South East Queensland Residential End Use Study (SEQREUS) (Beal and Stewart, 2011). Households from Brisbane, Sunshine Coast and Gold Coast were utilised in the sampling, due to their similar geographic (coastal) location and household consumption (Beal and Stewart, 2011). The data consists of a two week continuous smart water meter dataset recorded at a very fine resolution $(0.014 \mathrm{~L} /$ pulse at 5 second intervals). The sample sizes are shown in Table 3. This fine level of recorded data has allowed the water consumption to be separated into the relevant end uses using the Trace Wizard ${ }^{\mathrm{TM}}$ software.

Table 3 Household sample size and recorded periods

\begin{tabular}{lllll}
\hline Data & Period of analysis & $\begin{array}{l}\text { No. of } \\
\text { samples } \\
\text { (households) }\end{array}$ & $\begin{array}{l}\text { No. of } \\
\text { people }\end{array}$ & $\begin{array}{l}\text { Household } \\
\text { occupancy }\end{array}$ \\
\hline Winter 2010 & $14 / 06 / 2010$ to 27/06/2010 & 134 & 346 & 2.6 \\
Summer 2010-11 & 29/11/2010 to 12/12/2010 & 61 & 161 & 2.6 \\
Winter 2011 & $01 / 06 / 2011$ to 15/06/2011 & 64 & 175 & 2.7 \\
Summer 2011-12 & $01 / 12 / 2011$ to 14/12/2011 & 63 & 166 & 2.6 \\
Autumn 2012 & $18 / 03 / 2012$ to 31/03/2012 & 53 & 146 & 2.8 \\
Spring 2012 & 01/09/2012 to 15/09/2012 & 44 & 132 & 3.0 \\
Summer 2012-13 & 22/11/2012 to 05/12/2012 & 64 & 178 & 2.7 \\
\hline
\end{tabular}

In addition to the SEQREUS sample, the Hervey Bay smart water meter fleet water consumption data, which measured 2,494 single dwelling homes between 1 July 2008 and 1 July 2009, was included in the study. Although Hervey Bay is not specifically within SEQ, it is a coastal location and is of relative close proximity to the region. It is anticipated that household water use within the area will not differ significantly to the main study region (SEQ). Accurate end-use breakdown for this data was not possible due to its coarse nature (5 L/pulse and at hourly intervals), although Cole and Stewart (2012) have defined a consumption rate at which indoor $(<300 \mathrm{~L} / \mathrm{hr})$ and outdoor $(>300 \mathrm{~L} / \mathrm{hr})$ use can be separated for the area.

Demand patterns generated from the SEQREUS study were created at half-hourly intervals to allow for direct comparison with the standard time-step used by water utilities in the region for their network models. The hourly time-steps of the Hervey Bay data were converted into half-hourly time intervals by interpolating consumption values at every two intervals to allow for direct comparisons against the SEQREUS and utility demand patterns.

The SEQREUS dataset does not contain a full continuous year's water consumption information, which is required in developing $\mathrm{AD}, \mathrm{PD}$ and MDMM consumption patterns. Undertaking flow trace analysis to separate annual smart water meter data into its end uses is a labour-intensive process. Furthermore, although the Hervey Bay fleet has the required period of data, the coarse nature of the records limits any separation into different end uses. Thus, the water consumption data for each sample period from the 
SEQREUS fleet were analysed individually and compared against one another to draw conclusions on the development of the final average consumption pattern for the SEQ region. Results were divided into two main categories for analysis: indoor use (shower, clothes washer, toilets, taps, dishwasher and bath) and outdoor use. The indoor use category also includes the leakage component.

\subsubsection{Summary of indoor consumption}

The total indoor consumption from the SEQREUS smart water fleet was found to be similar for all time periods, with consumption ranging from 118 litres per person per day $(\mathrm{L} / \mathrm{p} / \mathrm{d})$ to $138 \mathrm{~L} / \mathrm{p} / \mathrm{d}$, with welldefined peaks in the morning ( 8 am to $9 \mathrm{am}$ ) and evening ( $6 \mathrm{pm}$ to $7 \mathrm{pm}$ ). Indoor diurnal peaks were normally higher in the morning than in the evening, with average daily peaks ranging from 11.2 litres per person per hour $(\mathrm{L} / \mathrm{p} / \mathrm{h})$ to $14.6 \mathrm{~L} / \mathrm{p} / \mathrm{h}$, and from $8.3 \mathrm{~L} / \mathrm{p} / \mathrm{h}$ to $10.3 \mathrm{~L} / \mathrm{p} / \mathrm{h}$, respectively. Morning indoor peak levels were mainly influenced by shower and clothes washer use, followed by taps and toilets. Evening indoor peaks were found to be mainly influenced by shower use (lower than the morning peak) and taps (similar to morning peaks), with less clothes washer and toilet use compared to in the morning. These findings are similar to those reported in other studies (Willis et al., 2011a; Beal and Stewart, 2011).

- Showers: Shower consumption was fairly constant for most periods of analysis ( $41 \mathrm{~L} / \mathrm{p} / \mathrm{d}$ to 46 L/p/d). Winter 2011 and Spring 2012 had the highest consumption of $51 \mathrm{~L} / \mathrm{p} / \mathrm{d}$ and $48 \mathrm{~L} / \mathrm{p} / \mathrm{d}$ respectively, and also accounted for the highest observed peaks of $7.5 \mathrm{~L} / \mathrm{p} / \mathrm{h}$ and $6.8 \mathrm{~L} / \mathrm{p} / \mathrm{h}$ respectively. Diurnal patterns for showers across the seven periods were similar, peaking between 6:30 am to 7:30 am, normally within the range of 4.8-5.2 L/p/h. An evening peak was also apparent at $6 \mathrm{pm}$, although this was not as high as the morning peak, ranging from 3.4 $\mathrm{L} / \mathrm{p} / \mathrm{h}$ to $4.7 \mathrm{~L} / \mathrm{p} / \mathrm{h}$.

- Clothes washer: Clothes washer consumption showed a steady decline over the sample period, with consumption being highest in Winter 2010, at $32 \mathrm{~L} / \mathrm{p} / \mathrm{d}$ and peaking at $4.9 \mathrm{~L} / \mathrm{p} / \mathrm{h}$. The decline was credited to a particularly effective intervention study, which informed the SEQREUS residents of their end-use consumption, resulting in decreased clothes washer use (Beal and Stewart, 2011). Diurnal patterns for the clothes washer followed a similar shape, with peaks ranging from $3.0 \mathrm{~L} / \mathrm{p} / \mathrm{h}$ to $4.6 \mathrm{~L} / \mathrm{p} / \mathrm{h}$, normally at 9 am and $10 \mathrm{am}$, and tailing off as the day progressed. Consumption values ranged between $23 \mathrm{~L} / \mathrm{p} / \mathrm{d}$ and $30 \mathrm{~L} / \mathrm{p} / \mathrm{d}$.

- Toilets: Toilets were the most constant end use, with consumption normally between $22 \mathrm{~L} / \mathrm{p} / \mathrm{d}$ to $28 \mathrm{~L} / \mathrm{p} / \mathrm{d}$ and peaks ranging from $1.9 \mathrm{~L} / \mathrm{p} / \mathrm{h}$ to $2.4 \mathrm{~L} / \mathrm{p} / \mathrm{h}$. The end-use pattern for toilets shows similar shapes for all periods, with a peak occurring at $8 \mathrm{am}$, followed by relatively constant consumption throughout the day, not exceeding $1.5 \mathrm{~L} / \mathrm{p} / \mathrm{h}$.

- Taps: Consumption values for taps decreased over the period of analysis, resulting in the wide range of $16 \mathrm{~L} / \mathrm{p} / \mathrm{d}$ to $28 \mathrm{~L} / \mathrm{p} / \mathrm{d}$, although the diurnal patterns remained the same. There were two similar peaks over the analysis periods: in the morning between 8 am to $9 \mathrm{am}$, and another at about $7 \mathrm{pm}$ in the evening. However, in line with the fall in consumption, over time, these peaks have also started decreasing (from $2.4 \mathrm{~L} / \mathrm{p} / \mathrm{h}$ to $1.4 \mathrm{~L} / \mathrm{p} / \mathrm{h}$ ).

- Dishwasher: Dishwasher use was one of the lowest consuming end uses, not exceeding 2 per cent of total indoor demand in all periods. The consumption ranges were also constant (2.0-2.5 $\mathrm{L} / \mathrm{p} / \mathrm{d}$ ), with the main peak occurring in the evening at $8 \mathrm{pm}$ to $9 \mathrm{pm}$, and another small peak in the morning, both of which were fairly low $(<0.3 \mathrm{~L} / \mathrm{p} / \mathrm{h})$.

- Bath: Along with dishwashers, bath use had one of the lowest consumptions (1.1-2.3 L/p/d), comprising not more than 2 per cent of indoor use. However, an above-average consumption was observed in Spring 2012 (5.0 L/p/d), with the highest peak of $1.9 \mathrm{~L} / \mathrm{p} / \mathrm{h}$ occurring at this time. 
- Post-meter leakage: Leakage was found to vary, with a high of $9 \mathrm{~L} / \mathrm{p} / \mathrm{d}$ during the initial set of readings (Winter 2010) followed by a drastic reduction to $2.8 \mathrm{~L} / \mathrm{p} / \mathrm{d}$ in the subsequent periods (Summer 2010, Winter 2011, Summer 2011). Following periods showed an increase in leakage $(6 \mathrm{~L} / \mathrm{p} / \mathrm{d}-8 \mathrm{~L} / \mathrm{p} / \mathrm{d})$, although not as high as initial observations. Leakage flow ranged between $0.05 \mathrm{~L} / \mathrm{p} / \mathrm{h}$ and $0.5 \mathrm{~L} / \mathrm{p} / \mathrm{h}$ for all periods, with spikes in leaks apparent, but not exceeding 0.6 $\mathrm{L} / \mathrm{p} / \mathrm{h}$.

\subsubsection{Developing the average indoor consumption patterns for each end use}

Developing the average indoor end-use consumption patterns

With consumption values differing for each end use over the different periods, the average pattern will be formulated for each end use using population averaged values from all periods; that is, total consumption over the seven periods divided by the total consuming population in the same period, to present a more representative average consumption pattern for the region. This will allow for more variance of consumption values of the different end uses to be considered, while still maintaining the shapes of their consumption patterns.

\section{Developing the average pattern for post-meter leakage}

The householder has little control over leakage unless measures are taken to identify and rectify the problem. This latter possibility was demonstrated by Beal and Stewart (2011), whose reported leakage intervention resulted in lower leakage (post Winter 2010 results); although the increase in leakages in later periods indicates an ongoing requirement for leakage identification and communication to reduce this wastage (Britton et al., 2013; Beal and Stewart, 2011).

Leakage peaks show no apparent association with any one appliance, although there is a slight resemblance to household water use patterns, with leakage more obvious over the day and lower during the night. This indicates that, while there is a steady leakage flow over the day, higher leaks would occur during the use of other household water appliances. Beal and Stewart (2011) showed a weak correlation with toilets $\left(\mathrm{R}^{2}=0.45\right)$ in diurnal pattern analysis, although other combinations are also possible, including post-meter pre-appliance leaks (plumbing between post-meter and before-appliance use), or leaking taps and showers.

Due to the uncertainties involved in the estimation of leakages, the average leakage pattern is taken to be constant throughout the day. From the seven recorded periods in the SEQREUS data, an average leakage consumption of $5.93 \mathrm{~L} / \mathrm{p} / \mathrm{d}$ was obtained, corresponding to an equivalent hourly flow of 0.25 $\mathrm{L} / \mathrm{p} / \mathrm{h}$.

\section{Development and verification of average indoor diurnal patterns}

Combining the consumption patterns for the various indoor end uses presents the total indoor diurnal pattern in Fig. 2. The developed pattern displays a good match with the indoor consumption profiles of the various time periods, with the shapes and times of peaks matching well, although consumption values differ. 


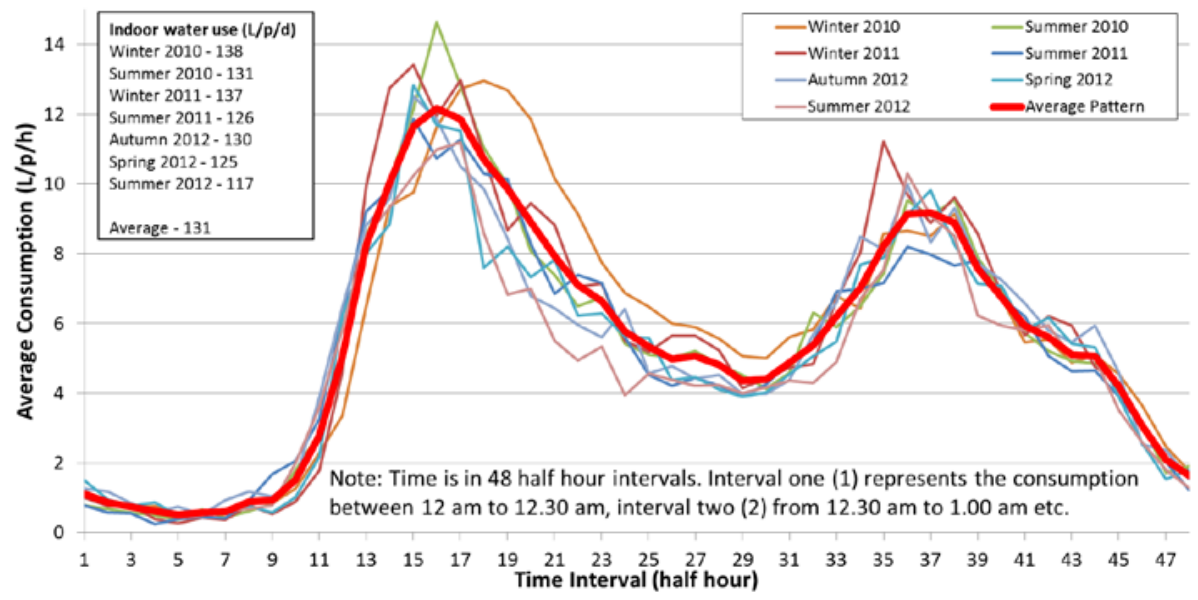

Fig. 2 Diurnal patterns of total indoor uses for various periods

Indoor consumption patterns from two other smart water meter studies (Cole and Stewart, 2012; Umapathi et al., 2013) carried out around SEQ with an approximate year's worth of data were developed for comparison and verification against the obtained average. As the consumption values differed for the patterns, they were normalised against their total indoor demand to provide for a more direct comparison. The obtained average pattern matched well with the indoor consumption patterns from the other studies, as shown in Fig. 3. This demonstrates the similarities in indoor consumption trends within this particular region, although this may not be true elsewhere.

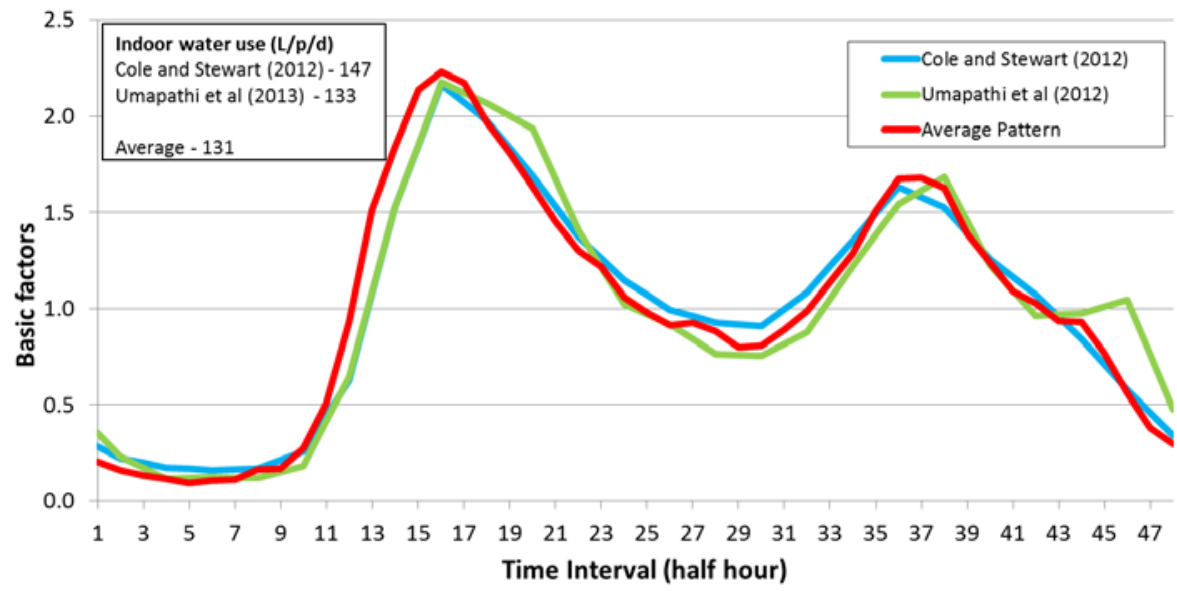

Fig. 3 Comparison of indoor consumption (with leaks) against other studies

\subsubsection{Developing the outdoor consumption pattern}

Outdoor usage occurs mainly during the day and is variable throughout the end use read periods, making it difficult to analyse properly. The developed average pattern for SEQ is shown in Fig. 4. A visual observation of the outdoor consumption values over the seven periods indicated three distinct levels of usage (Fig 4):

- Low-level (<10 L/p/d)—Winter 2010, Summer 2010, Winter 2011

- Mid-level (10-35 L/p/d)-Summer 2011 and Autumn 2012

- High-level (>35 L/p/d)—Spring 2012 and Summer 2012.

Outdoor consumption patterns for each of these three groups were created to allow a more comparable analysis of these end-use patterns. In low outdoor consumption periods $(<10 \mathrm{~L} / \mathrm{p} / \mathrm{d})$, the pattern was 
spread relatively evenly over the day, with fairly constant consumption observed between 10 am to 5 $\mathrm{pm}$ and no pronounced peak in the morning. General morning and evening total demand peaks were not affected, as outdoor consumption values were fairly low and only added $0.2 \mathrm{~L} / \mathrm{p} / \mathrm{h}-0.7 \mathrm{~L} / \mathrm{p} / \mathrm{h}$ of demand. The outdoor demand pattern in mid-level consumption periods $(10-35 \mathrm{~L} / \mathrm{p} / \mathrm{d})$ was similar to low consumption periods, with fairly constant demand between $7 \mathrm{am}$ to $5 \mathrm{pm}$ and an observed average peak of $1.5 \mathrm{~L} / \mathrm{p} / \mathrm{h}$, which would have a minimal effect on the morning and evening peaks (Fig 4). The periods with high outdoor consumption had more variation in peak flows, with peaks occurring between 7 am and $8 \mathrm{am}(3.7 \mathrm{~L} / \mathrm{p} / \mathrm{h})$ and $5 \mathrm{pm}$ and $6 \mathrm{pm}(5 \mathrm{~L} / \mathrm{p} / \mathrm{h})$, and usage at about $3 \mathrm{~L} / \mathrm{p} / \mathrm{h}$ between these periods (Fig 4).

The stochastic nature of analysing indoor and outdoor consumptions within the Hervey Bay area and the coarse capture of consumption data resulted in outdoor consumption being present during the early morning hours. This is not representative of current conditions, as outdoor consumption normally occurs during the day and tails off after evening hours. Diurnal pattern results from other end-use studies (Athuraliya et al., 2012; Beal and Stewart, 2011) have also shown that there is minimal external use in the early hours of the day. Outdoor consumption profiles in Fig. 4 show the sporadic nature of outdoor use in the SEQREUS data, a low sampled area, with spikes occurring at time intervals where usage occurs. In contrast, the larger sample size and coarse nature of the Hervey Bay fleet data resulted in a smoother outdoor consumption curve. It is also noted that there is a simple and similar trend in all the curves, where lower outdoor water usage is noted in the morning than in the evening. For these reasons, the diurnal pattern for Hervey Bay will be incorporated for use in the average demand pattern, with early morning flow reduced to minimal flow, and afternoon flows increased to account for the higher flows observed in the SEQREUS data.

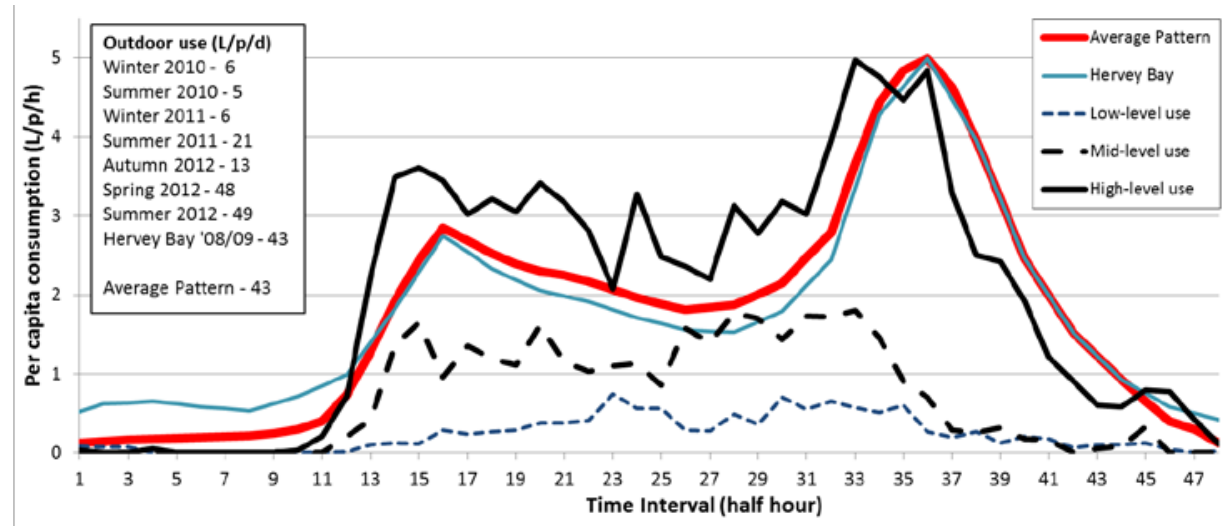

Fig. 4 Outdoor water usage patterns of various levels of use in SEQ and Hervey Bay

\subsubsection{Developing the total average diurnal pattern for the SEQ region}

The diurnal patterns for individual indoor end use have been revealed to follow a similar pattern irrespective of the period for which they were recorded. Leakage, which had no apparent association with any one appliance, was taken to be constant throughout the day. Outdoor consumptions followed similar trends, regardless of the level of outdoor consumption, mainly peaking in the evenings. Average patterns for each end use were created and combined to develop the average diurnal pattern (see Fig. 5) for the SEQ region. This bottom-up approach enables a more robust development of demand patterns due to the application of individual empirically-based water end-use consumption data, presenting an improved outcome compared to the traditional top-down approach, which relies mainly on historical total AD demand curves updated to fit current demand values. 


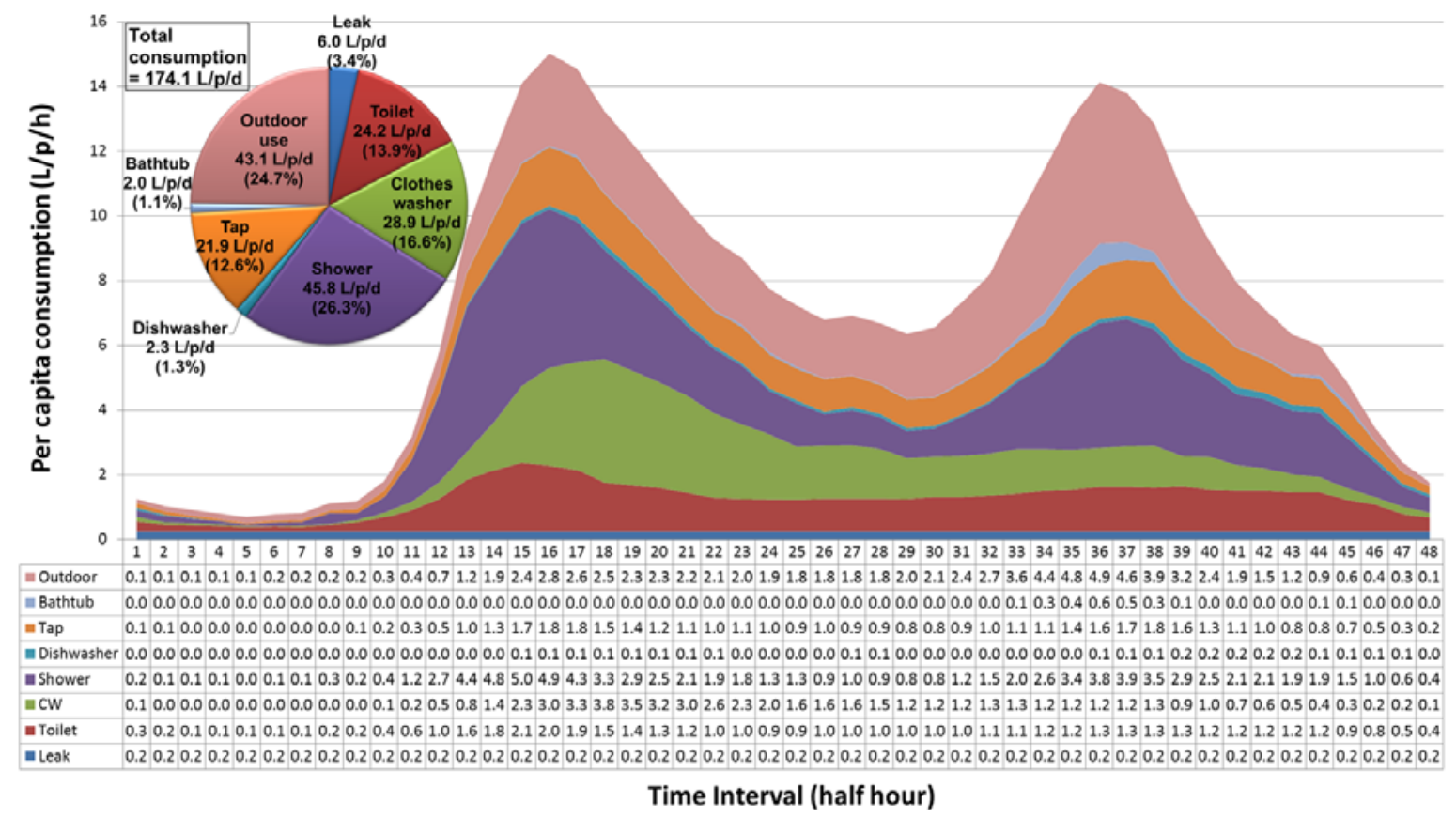

Fig. 5 Developed diurnal pattern consumption using a bottom-up end use-based approach

\subsection{Step 3: Normalise demand patterns for each end-use}

End uses were normalised (factored) as explained in section 3.1 to set the foundations for creating diurnal patterns using the stipulated $\mathrm{AD}$ value provided by the water utility. The final averaged, normalised end-use patterns are shown in Fig. 6.

Normalised diurnal pattern comparisons of each indoor end use, over the different periods and the final average pattern, showed similarities in their distribution factors and peaks, indicating the repetitiveness of householders' use of water appliances (Fig. 6). This also served as further verification in using consumption patterns over the various periods to develop the average end use patterns, as consumption for each end use, although different in volume, will follow relatively similar rates of use throughout the day. 

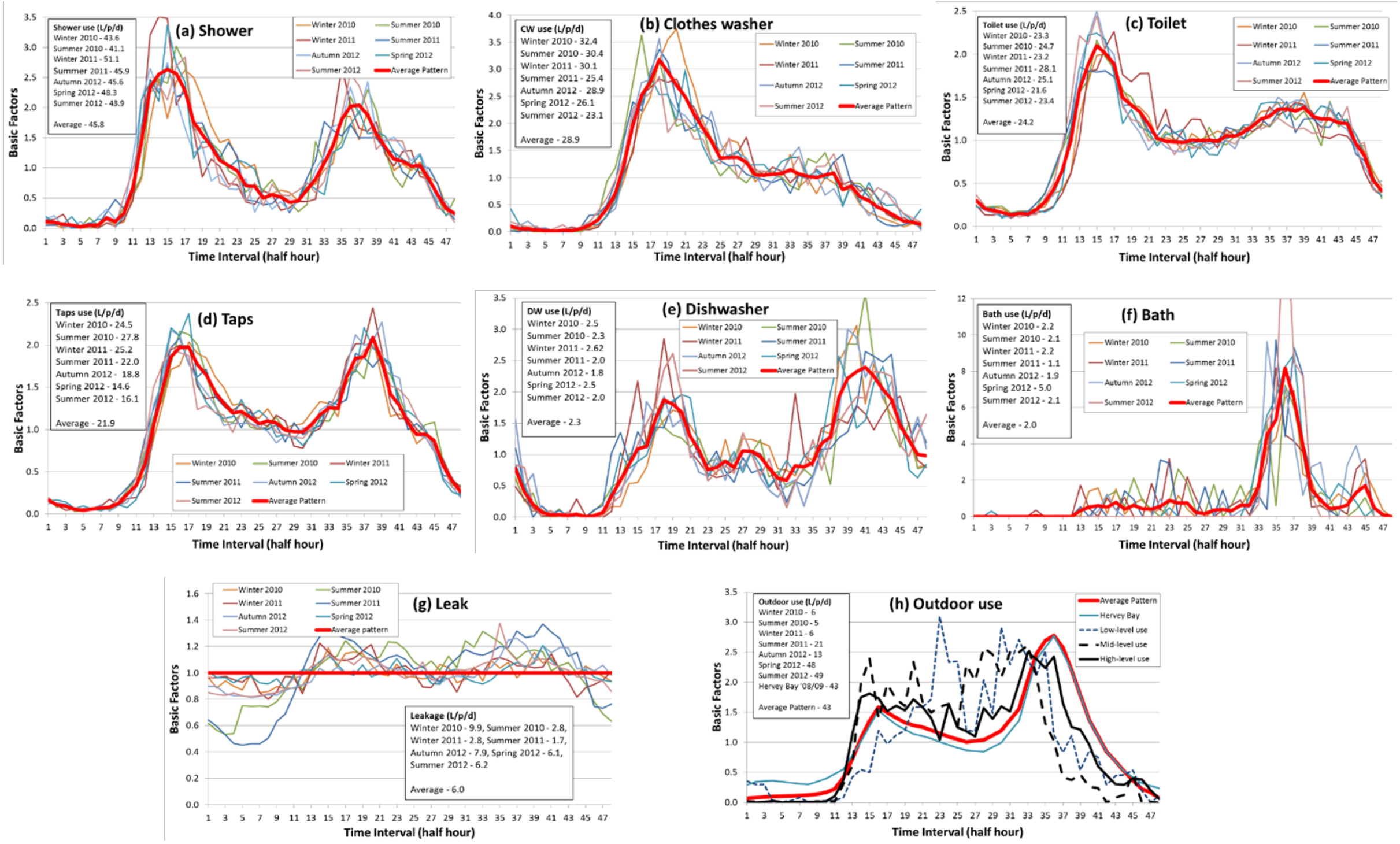

Fig. 6 Normalised end-use demand patterns for recorded SEQ data 


\subsection{Step 4: Estimate indoor and outdoor consumption splits}

A utility assigned AD consumption of $220 \mathrm{~L} / \mathrm{p} / \mathrm{d}$ (SEQ Code, 2013) was used for this example to develop an AD pattern for an area (Gold Coast) within the SEQ region. Although the value is well above that reported in the SEQREUS and the Queensland Water Commission (QWC) of $145 \mathrm{~L} / \mathrm{p} / \mathrm{d}$ and $154 \mathrm{~L} / \mathrm{p} / \mathrm{d}$ respectively (Beal and Stewart, 2011), as well as that developed in this study $(174 \mathrm{~L} / \mathrm{p} / \mathrm{d}$; see Fig. 5), it is a conservative and prudent approach for water supply planning (QWC, 2010). The cautious estimate takes into account the time frames for providing the water supply infrastructure and the levels of uncertainty; for example, consumer behavioural changes, population growth and potential impacts of climate change (QWC, 2010).

Indoor and outdoor consumption splits of the total $\mathrm{AD}$ consumption are required, as they affect final diurnal patterns differently depending on their consumption volume. Ideally, the splits in the two consumption profiles are identified from the smart water meter data. However, as data was obtained in a period surrounding a drought (i.e. not restricted water use but still less inclination to use water outdoors), seasonal water use had not yet rebounded and it was unclear to what the long-term patterns for outdoor water use would be in the future. Furthermore, due to the restricted length of recorded SEQREUS data, the seasonal influences on water consumption were not fully captured. This is especially important as variations in the climate due to seasonal changes affect household consumption levels, with outdoor consumption more affected than indoor consumption (Cole and Stewart, 2012). Hence, the modelling approach incorporated the indoor and outdoor water splits from local utility design codes and analysis of local end-use studies, which captured greater fluctuations of the outdoor end-use. Within the SEQ region, the outdoor component sourced from the SEQ Water Strategy (QWC, 2010) is approximately $60 \mathrm{~L} / \mathrm{p} / \mathrm{d}$, leaving $160 \mathrm{~L} / \mathrm{p} / \mathrm{d}$ as the indoor consumption.

An alternative method of obtaining the indoor and outdoor consumption split is through analysis of locally conducted end-use studies. Plotting the indoor and outdoor consumptions against total household consumption from results of various end-use studies exhibits a linear trend (Fig 7). The resulting equations can then be used to estimate the indoor and outdoor splits of total AD consumption. An example produced for this study is shown in Fig. 7 based on water consumption studies (Beal and Stewart, 2011; Cole and Stewart, 2012; Mead 2008; Umapathi et al., 2013, Willis et al., 2011a) undertaken in the SEQ region.

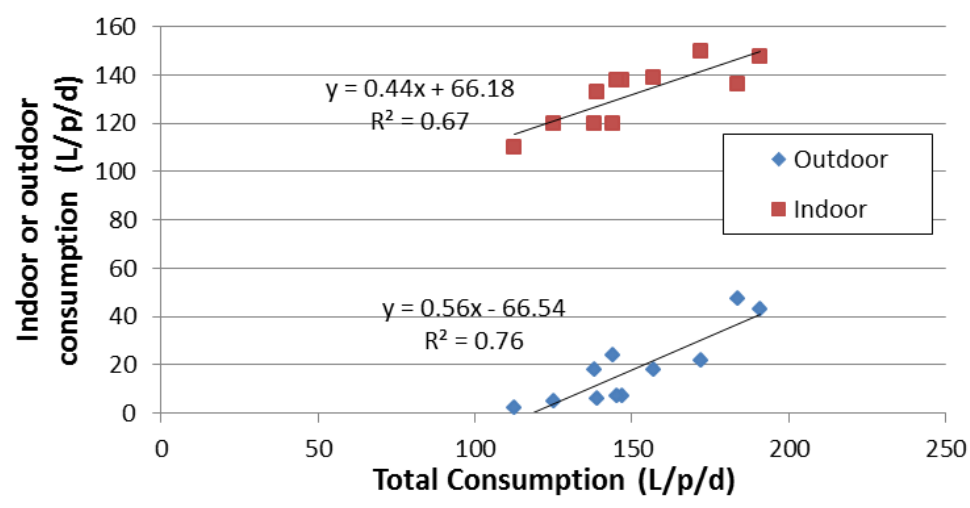

Fig. 7 Indoor and outdoor consumption relationship to total consumption on AD within the SEQ region

From the resulting equations presented in Fig 7, the indoor and outdoor components were estimated at $163 \mathrm{~L} / \mathrm{p} / \mathrm{d}$ and $57 \mathrm{~L} / \mathrm{p} / \mathrm{d}$ respectively, for a total water use of $220 \mathrm{~L} / \mathrm{p} / \mathrm{d}$. These equations are valid only if total water use is more than $120 \mathrm{~L} / \mathrm{p} / \mathrm{d}$. The obtained outdoor estimate is a close representation of the value provided in the QWC (2010) report. For consistency, the QWC (2010) split was used to model the demand patterns within this study; that is, $60 \mathrm{~L} / \mathrm{p} / \mathrm{d}$ for outdoor and $160 \mathrm{~L} / \mathrm{p} / \mathrm{d}$ for indoor. 


\subsection{Step 5: Update volumes for each indoor end use}

The outlined methodology requires the distributions for indoor end use, in percentage terms relative to total indoor consumption, to develop the estimated consumption patterns. In the current study, the distribution for each end use was obtained from the average consumption values developed for the study (See Fig. 5). The distributions are shown in Table 4. In the absence of high resolution smart water meter data, indoor end-use distributions from local end-use studies should be gathered where possible; an example of which is presented in Table 4 (from Beal and Stewart, 2011; Willis et al., 2011a). The distributions for each end use from these studies varied, but all were within a suitable range of acceptance. Choosing a value within this range and ensuring that the percentage indoor distribution is not exceeded; that is, is not more than $100 \%$, will provide suitable consumption values for each indoor end use.

Table 4 Indoor end-use distributions from local end-use studies and the distribution used within this study

\begin{tabular}{lrrr}
\hline End-use & $\begin{array}{r}\text { Indoor end-use } \\
\text { distribution ranges }\end{array}$ & $\begin{array}{r}\text { \%age } \\
\text { used in study }\end{array}$ & $\begin{array}{r}\text { Modelled demand } \\
\text { values (L/p/d) }\end{array}$ \\
\hline Leak & $1 \%-8 \%$ & $4.4 \%$ & 7.0 \\
Toilet & $15 \%-24 \%$ & $18.3 \%$ & 29.3 \\
Clothes washer & $20 \%-25 \%$ & $22.1 \%$ & 35.3 \\
Shower & $30 \%-36 \%$ & $35.4 \%$ & 56.6 \\
Dishwasher & $1 \%-2 \%$ & $1.7 \%$ & 2.8 \\
Tap & $15 \%-23 \%$ & $16.6 \%$ & 26.6 \\
Bath & $1 \%-2 \%$ & $1.5 \%$ & 2.4 \\
\hline \multicolumn{3}{r}{} \\
\hline
\end{tabular}

\subsection{Step 6: Develop final AD demand pattern}

Estimated daily consumption volumes for each indoor end use have been defined in Table 4 . Converting these volumes into average hourly flow values and multiplying them by the factors at each time interval for their respective normalised end-use curves, created initially (see Fig. 6), will present a diurnal consumption curve for each indoor end use in terms of flow values. Similarly, the obtained outdoor consumption $(60 \mathrm{~L} / \mathrm{p} / \mathrm{d})$ can be applied to the normalised outdoor demand curve (See Fig. 6) to develop the AD outdoor consumption profile. The end-use consumption patterns can then be combined to provide a final $\mathrm{AD}$ consumption pattern.

\subsection{Step 7: Develop peak demand curves}

\subsubsection{Analysis of PD and MDMM diurnal patterns}

Ideally, the high resolution SEQREUS data would be used to develop the PD and MDMM profiles using the outlined methodology. However, as a full year's data was not available for the SEQREUS fleet, and due to the time-consuming process of segregating smart water meter data into the different end uses, the Hervey Bay fleet data was used in the analysis of the PD and MDMM parameters. The SEQREUS data is incorporated with the coarse-grained Hervey Bay data to finalise the PD and MDMM outdoor consumption profiles. Indoor and outdoor usage profiles were created separately.

\section{Indoor use}

Indoor consumption analysis of PD and MDMM for Hervey Bay showed that daily consumption volumes for the two parameters were $18 \%$ and $8 \%$ higher than AD demand, respectively (see Fig. 8), while indoor flows were on average $20 \%$ and $10 \%$ higher, respectively, at each time interval (see Fig. 8). Hence, for a more conservative estimate of modelling indoor end-use profiles for these two parameters, each end use was increased by $20 \%$ for PD and 10\% for MDMM. 


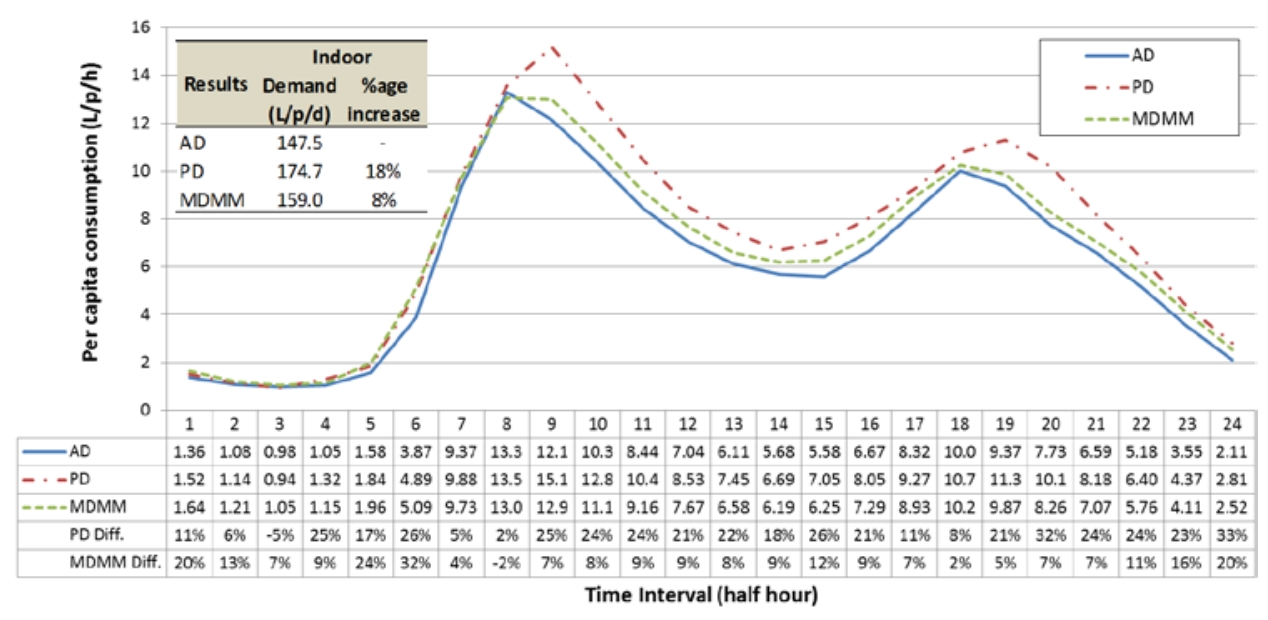

Fig. 8 Hervey Bay's indoor PD and MDMM flow comparisons against indoor AD flow at each time interval (inset table shows volume comparison)

\section{Outdoor use}

Outdoor consumption for Hervey Bay showed MDMM peaks to be stronger than AD peaks and PD peaks to be stronger than MDMM peaks, with a range of variations in flow differences at each time interval (see Fig. 9). As such, the method used to model indoor consumption profiles was not utilised for outdoor flows.

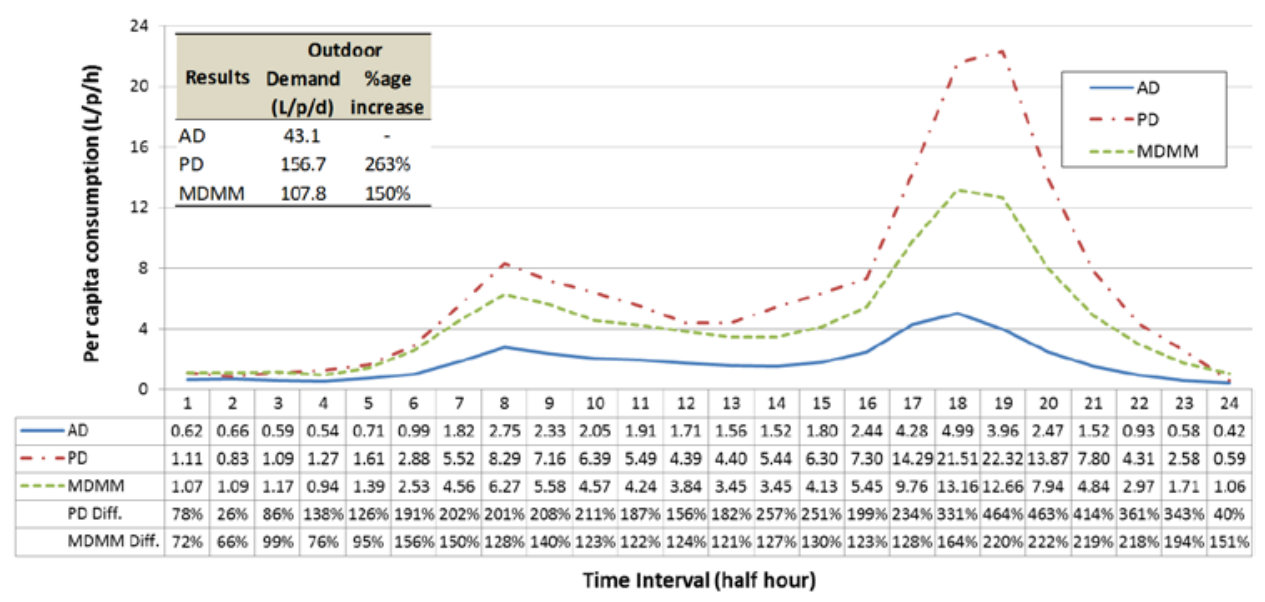

Fig. 9 Hervey Bay’s outdoor PD and MDMM flow comparisons against outdoor AD flow at each time interval (inset table shows volume comparison)

The outdoor consumption patterns of Hervey Bay were similar to SEQ patterns; that is, lower consumption observed in the morning than in the evening. To model outdoor flow, the normalised AD pattern developed for SEQ (see Fig. 6h) was used and scaled up to fit the PD and MDMM parameters of Hervey Bay outdoor flows. This allowed for the shape of the outdoor peak demand curves in the study to be maintained and more realistic peak factors used. PD factor (PDF) and peak hour on peak day factor (PHPDF) were required to develop the PD profile curves. PDF is the ratio of PD consumption to AD consumption, while PHPDF is the ratio of peak hour consumption against the average hourly consumption on AD. Similarly, the MDMM factor (MDMMF) and peak hour on MDMM factors (PHMDMMF) were required for the development of the MDMM outdoor consumption profiles.

The average outdoor profile was scaled with these factors by using the MS EXCEL ${ }^{\text {TM }}$ Solver tool to develop the outdoor consumption profiles for PD and MDMM. The MS EXCEL ${ }^{\text {TM }}$ Solver tool 
optimised the average consumption profile to create the required pattern by ensuring that peak factors are similar to obtained data. To develop the PD curve, the PDF and PHPDF used were 3.63 and 12.42, respectively. The MDMM profile was constructed using MDMMF at 2.5 and PHMDMMF at 7.32. Fig. 10 presents the developed PD and MDMM curves, plotted alongside the respective Hervey Bay peak curves. Equation 1, which is utilised by the local utility (GCW 2009) to scale up AD factors to peak factors for each time interval, was used to model outdoor peak curves:

$$
\operatorname{ModF}_{i}=a \cdot A D F_{i}^{2}+b \cdot A D F_{i}+c
$$

where: $\operatorname{ModF}_{i}$ is the modelled factor at time interval $\mathrm{i}, A D F_{i}$ is the base average factor at time interval $\mathrm{i}$, and $\mathrm{a}, \mathrm{b}$ and c are the constants optimised by MS EXCEL ${ }^{\mathrm{TM}}$ Solver. The peak factors (PHPDF with PDF or PHMDMMF with MDMMF) are the limiting conditions used in MS EXCEL ${ }^{\text {TM }}$ Solver.
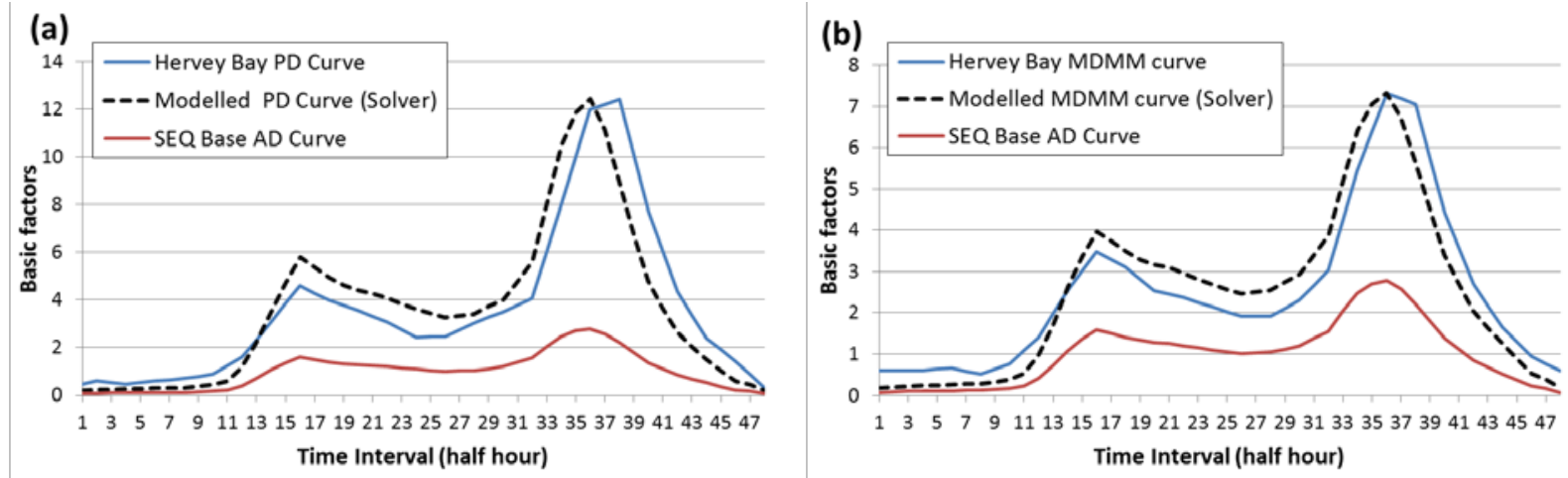

Fig. 10 (a) PD and (b) MDMM curves developed to match Hervey Bay peaks

\subsubsection{Final PD, AD and MDMM patterns}

The outdoor consumption flow profiles for PD and MDMM were developed by applying average hourly consumption for AD outdoor use to the profiles developed in Fig. 10. The outdoor and indoor end-use demand patterns were then combined to develop the PD and MDMM patterns (see Fig. 11, Fig. 13 and Fig. 14). The total consumption on PD and MDMM can be obtained from Equation 2:

$$
\text { Total consumption on PD or MDMM }=\left(P F_{\text {ind }} \times A D_{\text {ind }}\right)+\left(P F_{\text {out }} \times A D_{\text {out }}\right)
$$

where: $P F_{\text {ind }}$ is the peak factor for indoor consumption on PD or MDMM (peak factors are 1.2 and 1.1 respectively, in this study), $A D_{\text {ind }}=\mathrm{AD}$ indoor consumption, $P F_{\text {out }}$ is the peak factor for outdoor consumption on PD or MDMM (peak factors are 3.63 and 2.5 respectively, in this study) and $A D_{\text {out }}=$ AD outdoor consumption. 


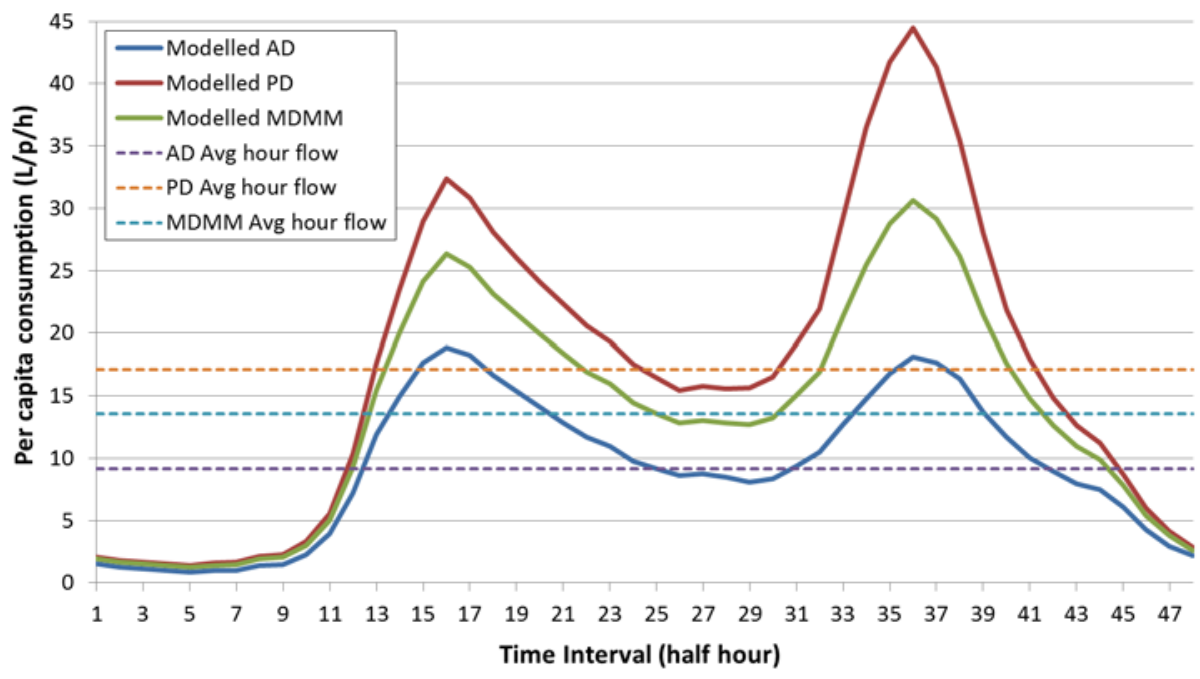

Fig. 11 Modelled AD, PD and MDMM demand flow patterns

\section{Final AD, PD and MDMM models and comparative assessment}

The proposed methodology has been applied to model the AD, PD and MDMM consumption patterns, which were then compared against modelled water utility patterns. A summary of peak values and factors from latest local guidelines (SEQ Code, 2013), Hervey Bay smart water meter fleet data (2008/09) and the modelled demand patterns are shown in Table 5.

Table 5 AD, PD and MDMM consumption values and factors provided by local guidelines, obtained from Hervey Bay and modelled from the outlined methodology

\begin{tabular}{|c|c|c|c|c|c|c|c|c|c|}
\hline \multirow{2}{*}{$\begin{array}{c}\text { Network } \\
\text { parameters }\end{array}$} & \multicolumn{3}{|c|}{ Utility (SEQ Code, 2013) } & \multicolumn{3}{|c|}{ Hervey Bay (2008/09) } & \multicolumn{3}{|c|}{ Modelled results } \\
\hline & $\begin{array}{r}\text { Demand } \\
(\mathrm{L} / \mathrm{p} / \mathrm{d})\end{array}$ & $\begin{array}{r}\text { Demand } \\
(\mathrm{L} / \mathrm{p} / \mathrm{h})\end{array}$ & Factors & $\begin{array}{r}\text { Demand } \\
(\mathbf{L} / \mathbf{p} / \mathbf{d})\end{array}$ & $\begin{array}{r}\text { Demand } \\
(\mathrm{L} / \mathrm{p} / \mathrm{h})\end{array}$ & Factors & $\begin{array}{r}\text { Demand } \\
\text { (L/p/d) }\end{array}$ & $\begin{array}{r}\text { Demand } \\
(\mathrm{L} / \mathrm{p} / \mathrm{h})\end{array}$ & Factors \\
\hline $\mathrm{AD}$ & 220.0 & - & - & 190.6 & - & - & 220.0 & - & - \\
\hline Peak at $\mathrm{AD}$ & - & 21.6 & 2.36 & - & 16.1 & 2.02 & - & 18.9 & 2.06 \\
\hline PD & 467.1 & - & 2.12 & 331.0 & - & 1.74 & 409.9 & - & 1.86 \\
\hline PHPD & - & 55.3 & 6.03 & - & 33.6 & 4.23 & - & 44.5 & 4.85 \\
\hline MDMM & 385.9 & - & 1.75 & 266.3 & - & 1.40 & 326.0 & - & 1.48 \\
\hline PHMDMM & - & 45.7 & 4.99 & - & 23.4 & 2.95 & - & 30.6 & 3.34 \\
\hline
\end{tabular}

\subsection{AD demand pattern comparisons}

The $\mathrm{AD}$ pattern developed from the proposed method utilises the $\mathrm{AD}$ consumption volume outlined by the utility $(220 \mathrm{~L} / \mathrm{p} / \mathrm{d})$. The outcome is a modelled AD pattern different to the utility curve, with a shift in timings and a reduction of the two peaks (see Fig. 12).

The main peak for the water utility's diurnal pattern occurs in the evening $(7: 30 \mathrm{pm})$, while the modelled AD pattern produced a main peak in the morning $(8 \mathrm{am})$. Furthermore, both modelled AD peaks occur earlier in the day, with the morning peak shifting 1.5 hours and evening peak by an hour. The utility pattern was derived from system monitoring conducted in 1999, and was subsequently modified to reflect the changing demand characteristics (GCW 2009). The change in demand patterns can be attributed to the changing lifestyles and behaviours of water consumers (Beal and Stewart, 2013; Browne et. al., 2013); for example, the shifts in demand peaks may be due to the prevalence of double income families (meaning that less water is used after $9 \mathrm{am}$; e.g. clothes washing by stay-at-home parent) or a move towards rising earlier in the day in the summer. 
The modelled AD pattern's main peak is lower than the utility's curve by $12 \%: 18.9 \mathrm{~L} / \mathrm{p} / \mathrm{h}$ compared with $21.6 \mathrm{~L} / \mathrm{p} / \mathrm{h}$. Whereas peaks in indoor water activities occur constantly in the morning (see Fig. 2 and Fig. 3), peaks in external water use normally occur in the evening (see Fig. 4 and Fig. 6h). This could suggest a change (reduction) in the consumption trend for outdoor end use, resulting in a 'flatter' outdoor demand curve than previously observed. This would explain the occurrence of the main peak in the evening during development of the base utility curve.

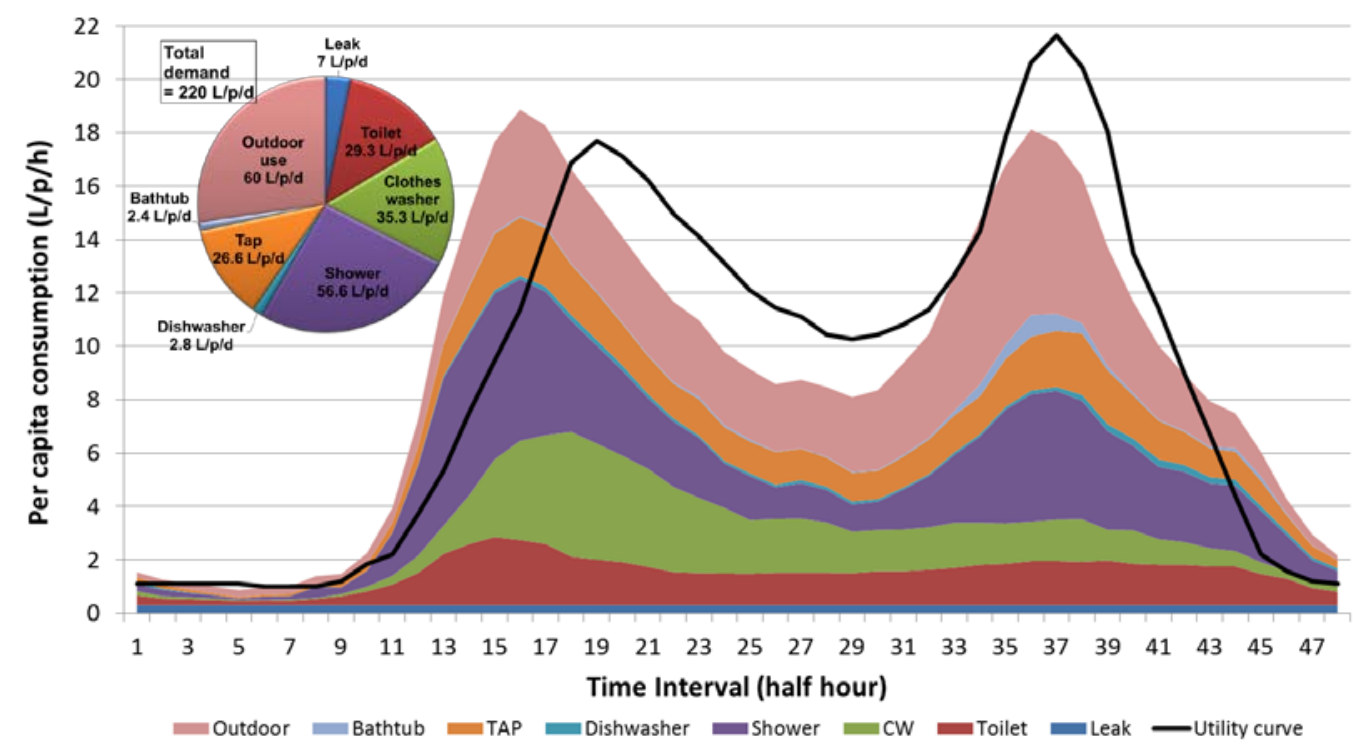

Fig. 12 Modelled and utility AD demand patterns

\subsection{PD and MDMM demand pattern comparisons}

The PD and MDMM consumption curves (see Fig. 13 and Fig. 14) were modelled from the base AD demand curves, resulting in earlier morning and evening peaks compared to the water utility's demand curve; similar to the results presented for the modelled AD consumption curve. The modelled PD and MDMM consumptions are lower than the water utility's by $12 \%$ and $15 \%$ respectively. Peaks have been reduced by $20 \%$ for the modelled PD curve and 33\% for the modelled MDMM curve compared to the respective utility patterns. This is in line with current consumption trends, whereby water demand generally has reduced over the years, with a reduction in peak demand also apparent from the Hervey Bay data and another study (Beal and Stewart, 2013).

Outdoor use was revealed as the driver of total morning and evening peaks, accounting for $45 \%$ and $70 \%$ on PD respectively, and 38\% and 60\%, respectively, for MDMM demands. Higher external usage, at 3.6 times and 2.5 times the $\mathrm{AD}$ outdoor demands in $\mathrm{PD}$ and MDMM respectively, resulted in the occurrence of main peaks in the evening, which is when most outdoor use occurs. The modelled outcome is supported by findings from other studies, which also report outdoor usage as the main driver of peak demands (Beal and Stewart, 2013; Cole and Stewart, 2012; Heinrich, 2007; Willis et al., 2011a). 


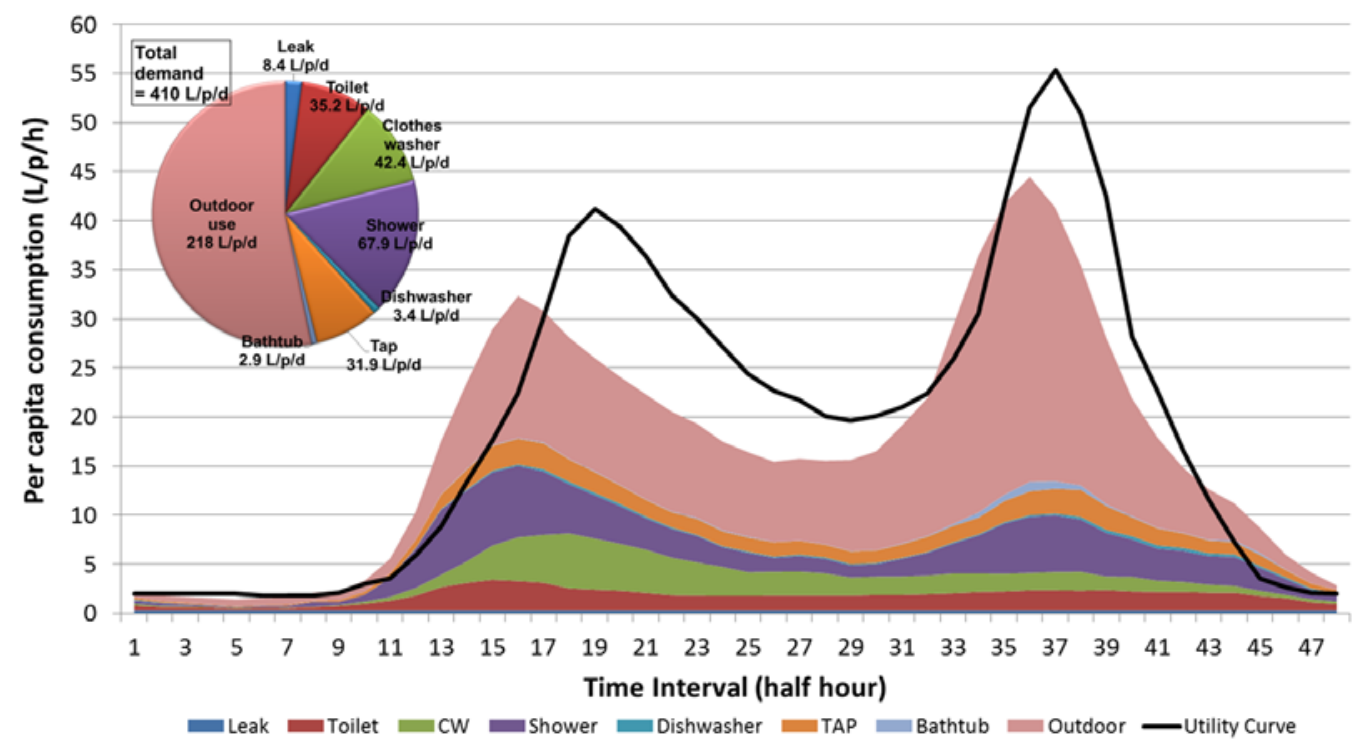

Fig. 13 Modelled and utility PD demand patterns

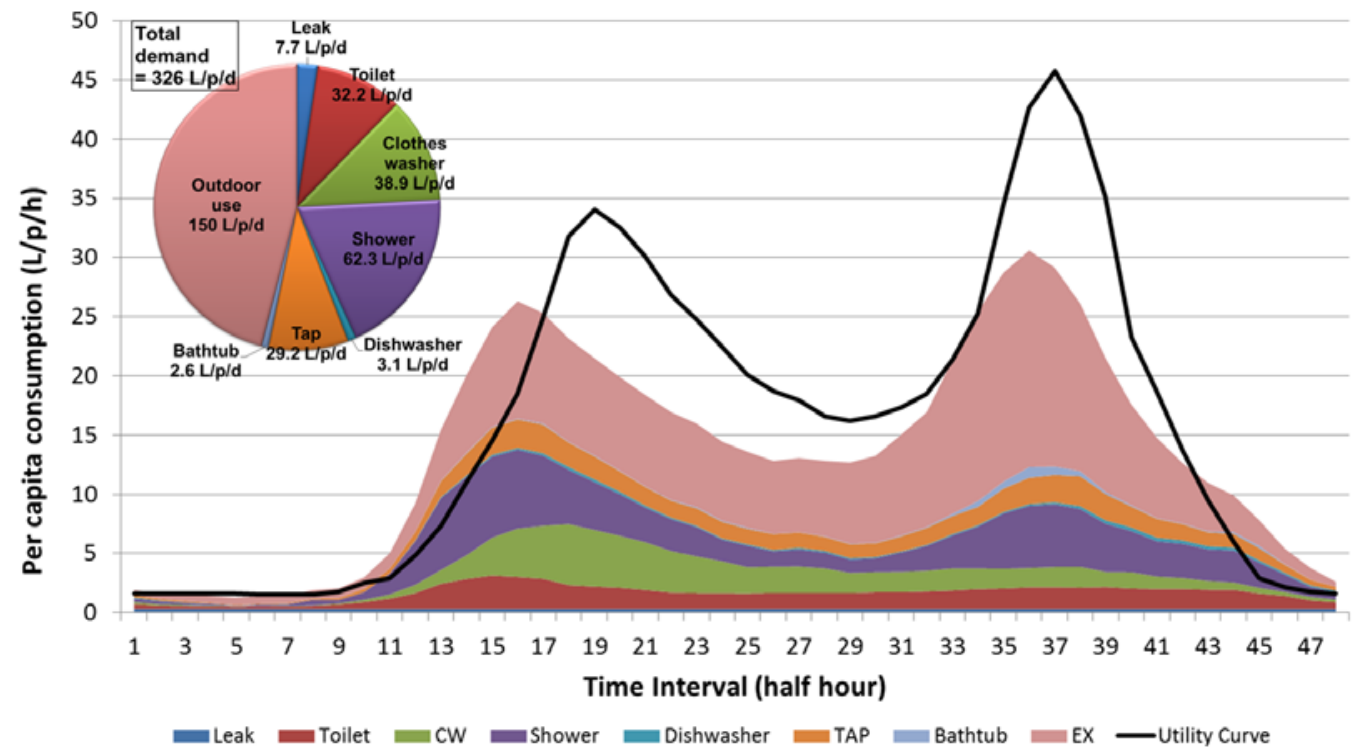

Fig. 14 Modelled and utility MDMM demand patterns

\subsubsection{Implications of reduced peak demand}

Information on peak demand patterns is required for the design of water infrastructure such as pumps, pipes and storage reservoirs. The latest PD and MDMM factors recorded from the Hervey Bay smart water meter fleet were lower than guidance from the water utility (see Table 5). This can be attributed to a reduction in overall household water consumption due to the water conservation measures that have been implemented, such as water efficient appliances and water restrictions (Beal and Stewart, 2013; Makki et al., 2013). As a result, the modelled PD and MDMM factors are also below those set by the water utility. Furthermore, the Queensland Development Code (QDC) Mandatory Part (MP) 4.1 mandates all new developments to install water efficient devices and adopt a more conservative approach to water consumption (Beal and Stewart, 2013). This trend in lower peaking factors is likely to continue due to the higher penetration of water efficient technology as older dwellings are replaced with newer ones designed under this Code. Reductions in peak demand have the potential to defer or reduce upgrades of water distribution infrastructure and their subsequent involved costs (Beal and 
Stewart, 2013; Cole and Stewart, 2012; Carragher et al., 2012). Thus, as current demand-modelling techniques typically use historical data, superfluous infrastructure augmentation works could be occurring due to outdated modelling assumptions and not because they have reached their capacity. Smart water meters take into account these lower peak demands, which can be easily analysed through continuously recorded data. As such, and in line with updated modelling techniques, this allows for more accurate modelling of peak demand. Hence, estimation times of system upgrades would be more explicit, with the deferred financial savings used for other purposes by the water utility.

\section{Study implications}

\subsection{Smart water meters' limitations and capabilities}

The advent of smart water metering has enabled customer water demand to be captured continuously in second, minute or hourly intervals at higher data resolutions $(0.01 \mathrm{~L}$ to $1 \mathrm{~L})$, and for this data to be transmitted autonomously to a central database. End-use studies have shown that smart water meters capture both changes in water consumption trends and the latest households' consumption patterns and demands. Assuming that the smart water meter fleet can deliver at least hourly consumption data, the captured stochastic and dynamic nature of water demand for each household (see Fig. 15) can be sent remotely and uploaded into a water supply model, allowing for a bottom-up JIT network modelling to be adopted. This would present a more accurate replication of the current status of water supply networks and assist service providers in their operations and maintenance schedules, while also more accurately being able to determine water being lost in NRW. Also, very high resolution flow data can be disaggregated into the different water end use categories as demonstrated in this study (see Fig. 6). Such a capability of smart water meters has the additional benefits of implementing a time-of-use-tariff (e.g. Cole et al., 2012), instantaneous detection of post-meter leakage (e.g. Britton et al., 2013) and the ability to inform consumer of where exactly their water is being consumed through a visualisation tool (e.g. Stewart et al., 2010).

However, the high resolution data provided by newly installed fleets of smart water meters does not yet fully satisfy the design requirements for long-term water supply infrastructure planning. Until long-term smart meter datasets can be obtained, planners will need to adjust daily diurnal demand patterns and peaking factors based on estimated trends of future water use. Over time, it is envisaged that smart meter fleets will be able to improve such demand trend estimates and help to semi-automate this planning process. Furthermore, the rollout of high resolution smart meters in a city requires high, upfront capital cost (Boyle et al., 2013) and considerable work is still required for data collection and end-use classification; a time intensive manual process. This is set to change in the future with technology becoming mass produced and considerably less expensive. Moreover, promising research on automating end use classifications has resulted in devices being correctly identified at more than $70 \%$ of the time (Nguyen et al., 2013a, 2013b, 2014; Fontdecaba et al., 2013), with further research proposed to increase the accuracy of end-use analysis.

\subsection{Model limitations and capabilities}

With the known limitations of smart water meters, the proposed methodology provides an innovative updated method for modelling water demand using smart water meter data complimented with current modelling methods. Each end-use consumption profile has been defined and captured within the overall diurnal pattern, offering more flexibility in its usage as a demand forecasting tool in water network modelling. However, the obtained demand curves will only be valid for the area over which it was averaged, and not for a single home, where the daily demand patterns are sporadic and difficult to predict (Alcocer et al., 2004) as shown in Fig. 15, prohibiting its use in JIT network modelling. 
Additionally, the stochastic nature of the outdoor component, due to its discretionary nature and seasonal dependence, is not captured fully by the meters. As such, some uncertainty arises in the modelling of the outdoor component, although longer term data collected will further strengthen the validity of the modelled outdoor end use.

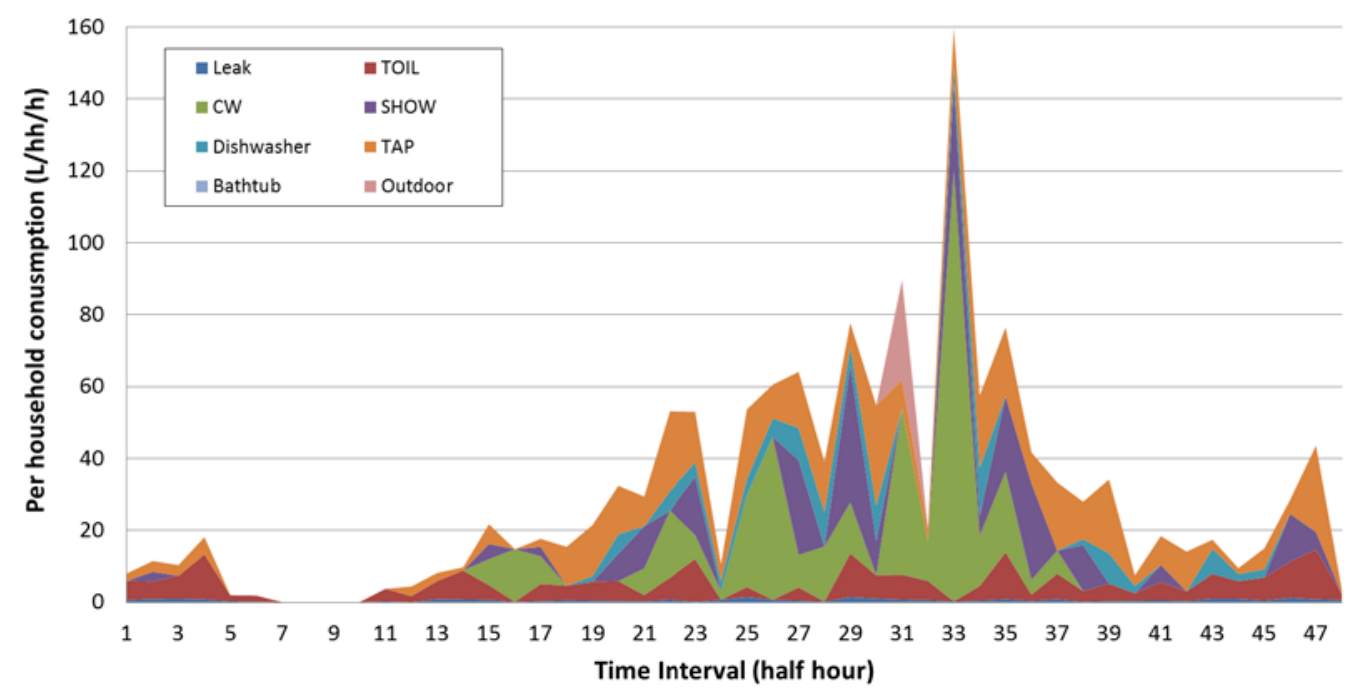

Fig. 15 Stochastic nature of a single household's water consumption pattern captured for a typical day

Within the study, a utility assigned AD demand $(220 \mathrm{~L} / \mathrm{p} / \mathrm{d})$, which takes into account levels of uncertainty, has been used to present the outlined methodology. However, the proposed modelling technique also allows alternative household consumption values to be used and adjustments to be made for volumes of each end use to reflect different areas' differing distribution in their end uses. For example, at the individual household level, potable demand may be obtained from bulk meters and through household audits, the approximate distributions of each end use, and hence their volumes, could be obtained. Alternatively, predictive models which estimate consumption values of end-uses, taking into account a household's profile (e.g. household composition, water stock inventory, socio demography structure) (Makki et al., 2013), can be used and calibrated with household bulk metering to estimate the end-use consumption for each home. The estimated volumes of each end-use can then be applied to the area's normalised diurnal curves, with the assumption that end-use patterns for each home are the same, to predict each household's demand patterns. Also, it is generally acknowledged that higher household occupancy equates to lower per capita consumption (Polebitski et al., 2010; Redhead et al., 2013; Roberts et al., 2012) due to more efficient water use; for example through fully loaded clothes and dishwashers and from outdoor water savings which is divided amongst more individuals (Polebitski et al., 2010). Hence, varying the demands for individual end-uses would allow households of different occupancies to be modelled, resulting in lower modelled peaks for high occupancy households and vice versa for lower occupancy households.

Current demand estimates and peaking factors for alternative water supplies in water planning guidance are fixed and do not allow for variations in their uses. The identification of the diurnal patterns for individual end uses can form the basis for modelling water demand for alternative water supplies, such as water recycling facilities and rainwater tanks and help to inform demand management strategies, including the use of water efficient appliances. This would allow for a more realistic representation of household consumption for alternative water supplies (Rathnayaka et al., 2011). 
Variations in water demand could be uploaded into nodes representing single households or a water supply zone, in a water supply network model that enables a more dynamic approach to network modelling. Hence, end use-based demand curves will allow utility planners to plan and more optimally design the water infrastructure, taking into account the end-use demand profiles and different usages of alternative water supplies within a water supply zone. In the future, through the installation of smart water meters over a citywide area, JIT modelling can be achieved, allowing water utility managers to predict and forecast the status of water infrastructure, as well as reaping other benefits from the technology.

\section{Conclusions}

The paper proposes a methodology utilising normalised average water end-use demand curves of a water supply zone as a foundation for developing various household demand patterns for use in network modelling. The methodology was applied in the SEQ region using the SEQREUS and Hervey Bay smart water meter data. Analysis of normalised indoor end-use consumption patterns of the SEQREUS smart water meter fleet demonstrated similarities in pattern shapes and peaks over the various periods, which was further verified by other local studies. Outdoor usage profiles showed a basic and similar trend, with consumption normally higher in the evening than in the morning.

Modelled AD peaks occurred in the morning, in contrast to the water utility's AD pattern, which had an evening peak, suggesting a greater influence of outdoor consumption for the base water utility's curve. Furthermore, modelled peaks in PD and MDMM were lower by 20\% and 33\% respectively, as potable water demand has generally decreased over the years. The end-use breakdown of water consumption showed that outdoor water use was responsible for the main peaks in modelled PD and MDMM consumption, as supported by other end-use studies (Beal and Stewart, 2013; Cole and Stewart, 2012; Heinrich, 2007; Willis et al., 2011a).

The study has also highlighted the importance of smart water meters as an efficient tool in the management, operation and planning of water infrastructure in the short to medium term, although approximate data is still useful for long term planning. Essentially, smart water meters require adequate penetration in a water supply zone to maximise their continuously gathered data. Recorded data from this technology can provide a foundation for developing demand curves, allowing for up-to-date household demand modelling and providing flexibility in modelling alternative water supplies. The widespread application of smart water meters is foreseeable in the future, as lower costs and quicker methods are developed for developing water end-use demand profiles to a high degree of accuracy. Through real-time modelling of latest trends in water consumption, the water supply network model can be optimised, resulting in the deferral or elimination of infrastructure augmentation and associated costs.

\section{References}

Alcocer YVH, Tzatchkov VVG, Buchberger SG, Arreguín FI, Feliciano D (2004), Stochastic Residential Water Demand Characterization, Proceedings of the World Water \& Environmental Resources Congress, ASCE-EWRI, Salt Lake City, UT, June 27-July 1

Aquacraft (2010) Trace Wizard® software version 4.1. 1995-2010 Aquacraft, Inc. Boulder, CO, USA.

Athuraliya A, Roberts P, Brown A (2012) Yarra Valley Future Water: Residential Water Use Study Volume 2-Summer 2012, Yarra Valley Water, Victoria

Beal C and Stewart RA (2011) South-East Queensland Residential End Use Study: Final Report, Urban Water Research Security Alliance Technical Report No. 47 
Beal C, Stewart R, Fielding K (2013) A novel mixed method smart metering approach to reconciling differences between perceived and actual residential end use water consumption. Journal of Cleaner Production 60:116-128

Beal C, Stewart RA (2013) Identifying Residential Water End-Uses Underpinning Peak Day and Peak Hour Demand. Journal of Water Resources Planning and Management. doi:10.1061/(ASCE)WR.1943-5452.0000357

Blokker EJM, Vreeburg JHG, Beverloo H, Klein Arfman M., Van Dijk, JC (2010a) A bottom-up approach of stochastic demand allocation in water quality modelling. Drinking Water Engineering and Science 3(1):43-51

Blokker EJM, Vreeburg JHG, Van Dijk, JC (2010b) Simulating residential water demand with a stochastic end-use model. Journal of Water Resources Planning and Management 136(1):19-26

Boyle T, Giurco D, Mukheibir P, Liu A, Moy C, White S, Stewart R (2013) Intelligent Metering for Urban Water: A Review. Water 5:1052-1081

Britton T, Stewart R, O’Halloran K (2013) Smart metering: enabler for rapid and effective post meter leakage identification and water loss management. Journal of Cleaner Production 54:166-176

Browne AL, Medd W, Anderson B (2013) Developing Novel Approaches to Tracking Domestic Water Demand Under Uncertainty_A Reflection on the "Up Scaling" of Social Science Approaches in the United Kingdom. Water Resources Management 27(4):1013-1035

Carragher BJ, Stewart RA, Beal CD (2012) Quantifying the influence of residential water appliance efficiency on average day diurnal demand patterns at an end use level: A precursor to optimised water service infrastructure planning. Resources, Conservation and Recycling 62:81-90

Cole G, Stewart RA (2012) Smart meter enabled disaggregation of urban peak water demand: precursor to effective urban water planning. Urban Water Journal 10(3):1-21

Cole G, O’Halloran K, Stewart RA (2012) Time of use tariffs: implications for water efficiency. Water Science \& Technology: Water Supply 12(1):90-100

Cook S, Sharma A, Chong M (2013) Performance Analysis of a Communal Residential Rainwater System for Potable Supply: A Case Study in Brisbane, Australia. Water Resources Management 27(14):4865-4876

Cook S, Sharma A, Gurung TR (2014) Evaluation of alternative water sources for commercial buildings: a case study in Brisbane, Australia. Resources, Conservation \& Recycling (in press)

CSIR (2003) Guidelines for Human Settlement Planning and Design, Volume 2, Chapter 9: Water Supply, Council for Scientific and Industrial Research: Building and Construction Technology, Report No. BOU/E2001, Pretoria, South Africa

DERM (2010) Planning Guidelines for Water Supply and Sewerage, Department of Environmental and Resource Management, Queensland Government

Duncan HP, Mitchell VG (2008) A stochastic demand generator for domestic water use. Paper presented at Water Down Under 2008 conference, Adelaide, April 14-17

Ferguson M (2011) Rainwater tank monitoring report: A 12 month one-minute interval data study of rainwater tank savings and energy use for 52 real life installations, Sydney Water Corporation

Fontdecaba S, Sánchez-Espigares JA, Marco-Almagro L, Tort-Martorell X, Cabrespina F, Zubelzu J (2013) An Approach to Disaggregating Total Household Water Consumption into Major EndUses. Water Resources Management 27(7):2155-2177

GCW (2009) Gold Coast Water (2009-A), “Desired Standards of Service Review 2008”, GHD Final Report Rev 3, October 2009

Heinrich, M. (2007), Water End Use and Efficiency Project (WEEP) - Final Report, BRANZ Study Report 159, BRANZ Ltd, Judgeford, New Zealand 
Heinrich M (2008) Water Use in Auckland Households: Auckland Water Use Study (AWUS) Final Report, BRANZ Ltd, Judgeford, New Zealand.

Lee M, Tansel B, Balbin M (2011) Influence of residential water use efficiency measures on household water demand: A four year longitudinal study. Resources, Conservation and Recycling 56(1):1-6

Lucas SA, Coombes PJ, Sharma AK (2010) The impact of diurnal water use patterns, demand management and rainwater tanks on water supply network design, Water Science \& Technology: Water Supply-WSTWS 10(1):69-80

Makki AA, Stewart RA, Panuwatwanich K, Beal C (2013) Revealing the determinants of shower water end use consumption: enabling better targeted urban water conservation strategies. Journal of Cleaner Production 60:129-146

Mayer PW, DeOreo WB (1999) Residential End Uses of Water, Aquacraft, Inc. Water Engineering and Management, Boulder, CO

Mayer PW, DeOreo WB, Towler E, Martien L, Lewis DM (2004) Tampa Water Department Residential Water Conservation Study. The impacts of high efficiency plumbing fixture retrofits in single family homes, Tampa Water Department and The United States Environmental Protection Agency, Boulder, CO

Mead, N. (2008), Investigation of Domestic Water End Use, Undergraduate Thesis, Faculty of Engineering and Surveying, University of Southern Queensland, Toowoomba, Australia

MOE (2008) Design Guidelines for Drinking Water Systems 2008 (PIBS 6881e), Ministry of the Environment, Ontario, Canada

Nguyen KA, Zhang H, Stewart RA (2013a) Development of an intelligent model to categorise residential water end use events. Journal of Hydro-environment Research 7(3):182-201,

Nguyen KA, Stewart RA, Zhang H (2013b) An intelligent pattern recognition model to automate the categorisation of residential water end-use events. Environmental Modelling \& Software 47:108127

Nguyen KA, Stewart RA, Zhang H (2014) An autonomous and intelligent expert system for residential water end-use classification. Expert Systems with Applications 41(2):342-356

Parker JM, Wilby RL (2013) Quantifying Household Water Demand: A Review of Theory and Practice in the UK. Water Resources Management 27(4):981-1011

Polebitski AS and Palmer RN (2010) Seasonal residential water demand forecasting for census tracts. Journal of Water Resources Planning and Management 136(1): 27-37

Proenca LC, Ghisi E (2010) Water end-uses in Brazilian office buildings. Resources, Conservation and Recycling 54(8):489:500

QWC (2010) South East Queensland Water Strategy, Queensland Water Commission, The State of Queensland, City East, Queensland

Rathnayaka K, Malano H, Maheepala S, Nawarathna B, George B, Arora M (2011) Review of residential urban water end-use modelling, 19th International Congress on Modelling and Simulation, Perth, Australia, December 12-16

Redhead M, Athuraliya A, Brown A, Gan K, Ghobadi C, Jones C, Nelson L, Quillam M, Roberts P, Siriwardene N (2013) Melbourne Residential Water End Uses Winter 2010/Summer 2012, Report 10TR5-001, Smart Water Fund, Melbourne, Victoria

Roberts P, Athuraliya A, Brown A (2011) Yarra Valley Future Water: Residential Water Use Study Volume 1-Winter 2010, Yarra Valley Water, Victoria

SEQ Code (2013) South East Queensland Water Supply and Sewerage Design and Construction Code, South East Queensland Code, Queensland. http://www.seqcode.com.au/storage/2013-07-01\%20\%20SEQ\%20WSS\%20DC\%20Code\%20Design\%20Criteria.pdf [accessed Aug 2013] 
Stewart RA, Willis RM, Giurco D, Panuwatwanich K, Capati B (2010) "Web-based knowledge management system: linking smart metering to the future of urban water planning”. Australian Planner 47(2):66-74

Thyer MA, Duncan H, Coombes P, Kuczera G, Micevski T (2009) A probabilistic behavioral approach for the dynamic modelling of indoor household water use, Paper presented at 32nd Hydrology and Water Resources Symposium, Newcastle, Australia, November 30-December 3

Todorovic B, Tsakiris G, Prodanovic D (2011) A pilot initiative for improved urban demand estimation based on stochastic analysis of water consumption. Water Utility Journal 1:19-29

Twort CA, Ratnayaka DD, Brandt MJ (2000) Water Supply (5 ${ }^{\text {th }}$ Edition), Elsevier

Umapathi S, Chong MN, Sharma AK (2013) Evaluation of plumbed rainwater tanks in households for sustainable water resource management: a real-time monitoring study. Journal of Cleaner Production 42:204-214

Water Corporation (2010) Perth residential water use study 2008/2009, Water Forever, Water Corporation, Western Australia

Willis R, Stewart RA, Panuwatwanich K, Capati B, Giurco D (2009) Gold Coast Domestic Water End Use Study. Australian Water Association Journal 36(6):84-90.

Willis RM, Stewart RA, Panuwatwanich K, Jones S, Kyriakides A (2010) Alarming visual display monitors affecting shower end use water and energy conservation in Australian residential households, Resources, Conservation and Recycling 54(12):1117-1127

Willis RM, Stewart RA, Williams PR, Hacker CH, Emmonds SC, Capati G (2011a) Residential potable and recycled water end uses in a dual reticulated supply system. Desalination 272(1-3):201-211

Willis RM, Stewart RA, Panuwatwanich K, Williams, PR, Anna LH (2011b) Quantifying the influence of environmental and water conservation attitudes on household end use water consumption. Journal of Environmental Management 92(8):1996-2009

Willis RM, Stewart RA, Giurco DP, Talebpour MR, Mousavinejad A (2013) End use water consumption in households: impact of socio-demographic factors and efficient devices. Journal of Cleaner Production 42:129-146

WSAA (2004) Water Supply Code of Australia, WSA 03 - 2002-2, Melbourne Retail Water Agencies Edition, Part 1: Planning and Design, Water Services Association of Australia, July 2004

Ysusi MA (2000) “Water Distribution Systems”, Chapter 3, System Design: An Overview, pp. 3.1 